\title{
Neural Lineage Differentiation From Pluripotent Stem Cells to Mimic Human Brain Tissues
}

\author{
Yean Ju Hong and Jeong Tae Do* \\ Department of Stem Cell and Regenerative Biotechnology, KU Institute of Science and Technology, Konkuk University, Seoul, \\ South Korea
}

OPEN ACCESS

Edited by:

Stephanie Michelle Willerth, University of Victoria, Canada

Reviewed by:

Khoon Lim

University of Otago, Christchurch,

New Zealand

Xuegang Yuan,

Florida State University, United States

*Correspondence:

Jeong Tae Do

dojt@konkuk.ac.kr

Specialty section:

This article was submitted to Biomaterials,

a section of the journal Frontiers in Bioengineering and Biotechnology

Received: 16 August 2019 Accepted: 22 November 2019 Published: 06 December 2019

Citation:

Hong YJ and Do JT (2019) Neural Lineage Differentiation From Pluripotent Stem Cells to Mimic Human Brain Tissues. Front. Bioeng. Biotechnol. 7:400. doi: 10.3389/fbioe.2019.00400
Recent advances in induced pluripotent stem cell (iPSC) research have turned limitations of prior and current research into possibilities. iPSCs can differentiate into the desired cell types, are easier to obtain than embryonic stem cells (ESCs), and more importantly, in case they are to be used in research on diseases, they can be obtained directly from the patient. With these advantages, differentiation of iPSCs into various cell types has been conducted in the fields of basic development, cell physiology, and cell therapy research. Differentiation of stem cells into nervous cells has been prevalent among all cell types studied. Starting with the monolayer 2D differentiation method where cells were attached to a dish, substantial efforts have been made to better mimic the in vivo environment and produce cells grown in vitro that closely resemble in vivo state cells. Having surpassed the stage of 3D differentiation, we have now reached the stage of creating tissues called organoids that resemble organs, rather than growing simple cells. In this review, we focus on the central nervous system (CNS) and describe the challenges faced in $2 \mathrm{D}$ and $3 \mathrm{D}$ differentiation research studies and the processes of overcoming them. We also discuss current studies and future perspectives on brain organoid researches.

Keywords: pluripotent stem cell, differentiation, neural, brain, organoid

\section{INTRODUCTION}

The ideal scenario for studying human physiology and diseases would be to study cells and tissues directly obtained from the source (e.g., patients). However, human cells or tissues are not easily available and even in cases where they are made available, research with human materials is limited, strictly controlled, and subject to ethical approval from the respective research ethics committees. Compared to other organs, brain tissue is much more difficult to obtain and is also more laborious in the experimental setting. To overcome this issue, immortalized primary human cells have been extensively used. However, immortalized cell lines could never simulate the physiology and function of normal cells in tissues, because of genetic and epigenetic changes such as alterations in gene expression patterns or delayed maturation occurring in the cells during the immortalization process (Farwell et al., 2000). As an alternative approach, animal models have been used to provide the needed tissue or cells. However, there are clear limitations in using animal models to study human disease and physiology. For example, many brain or neurological diseases affecting humans are not present in animals (Nestler and Hyman, 2010; Van der Worp et al., 2010). In addition, humans have complex brain structures distinct from those of other animals, which makes the use of animal models for human brain research unsuitable. The human cerebral cortex is composed of 
six layers, namely the ventricular zone (VZ), inner (iSVZ) and outer subventricular zone (oSVZ), intermediate zone (IZ), cortical plate $(\mathrm{CP})$, and marginal zone $(\mathrm{MZ})$, whereas the mouse cerebral cortex lacks the oSVZ layer (Zecevic et al., 2005). In addition, the smooth brain of a human fetus later becomes wrinkled to form sulci and gyri which is also not shown in mouse brain (Welker, 1990). Hence, human brain disorders often cannot be explained by the results obtained using animal models. On that note, it is made clear that only human cells should be used to investigate and identify the cause or mechanisms of human neurological diseases. If human cells are to be used, cells capable of both self-renewal and differentiation into specialized cells (i.e., stem cells) during in vitro cultivation would be the best option. Adult stem cells recovered from various tissues have a limited self-renewal ability and differentiation potential in vitro. On the contrary, pluripotent stem cells can differentiate into every cell type in the body and possess unlimited selfrenewal ability, making them a suitable cell type for research. Nowadays, induced pluripotent stem cells (iPSCs) can be easily established from differentiated cells through transduction of reprogramming factors (Takahashi and Yamanaka, 2006; Yu et al., 2007). One of the merits of using iPSCs is the potential to overcome the constraints of limited donor availability and ethical issues associated with human material use (Chun et al., 2010). Thus, many researchers have begun to use iPSCs as a model system for developmental and disease studies, using the differentiation technique and disease modeling, respectively (Saha and Jaenisch, 2009). So far, various cell types, including endodermal, mesodermal, and ectodermal lineages, have been generated from iPSCs and used in disease modeling in vitro (Hanna et al., 2007; Raya et al., 2009; Carvajal-Vergara et al., 2010; Liu et al., 2010; Yang et al., 2010; Brennand et al., 2011; Itzhaki et al., 2011; Yazawa et al., 2011). In particular, by differentiating patient-derived iPSCs into a neural lineage, study and modeling on a neurological disease which would otherwise be arduous to perform can be easily conducted. iPSCs have been differentiated into neural stem cells (NSCs) in a 3 dimensional (3D) environment, including neurospheres, and 2 dimensional (2D) NSCs, including rosette-types (Elkabetz et al., 2008) and primitive NSCs (Shin et al., 2019). Continuing efforts on the differentiation technology to mimic brain tissue in vitro using pluripotent stem cells have led to technical advances, such as the formation of a mini brain-like structure or brain organoids (Lancaster et al., 2013). In this review, we discuss the technical advances on neural differentiation model systems using pluripotent stem cells toward mimicking the brain tissue and present the obstacles that need be overcome and the future directions in the field.

\section{D NEURAL LINEAGE DIFFERENTIATION 2D Neural Lineage Differentiation From Pluripotent Stem Cells}

During gastrulation in mammals, the first neural structure that emerges is a form of neural tube consisting of a layer of neuroepithelial cells (Stiles and Jernigan, 2010). Neuroepithelial cells are early neural stem cells that can further differentiate into radial glial cells (RGCs), which are bipolar-shaped neural progenitor cells (NPCs) that can in turn produce both neurons and glial cells, including astrocytes and oligodendrocytes (Malatesta et al., 2000; Noctor et al., 2001; Tamamaki et al., 2001; Merkle et al., 2004). NSCs are tripotent cells that can differentiate into 3 neural lineage cell subtypes: neurons, astrocytes, and oligodendrocytes (Glaser et al., 2007). In addition, NSCs are known to reside in the subventricular zone (SVZ) of the lateral ventricle and subgranular zone (SGZ) of the adult brain hippocampus (Alvarez-Buylla and Lim, 2004). Neural stem cells can be cultured in vitro by isolating cells from in vivo niches of brain tissues. The "no new neuron hypothesis" was first challenged in 1889 by reports claiming that NSCs capable of producing neuron and glia cells were isolated from an embryonic rat forebrain (Temple, 1989). Since then, isolation of NSCs from the adult central nervous system has been successfully performed in various species of mammals (Reynolds and Weiss, 1992). Both mouse and human NSCs can be isolated and maintained in vitro in the presence of extrinsic factors, such as epidermal growth factor (EGF) and fibroblast growth factor 2 (FGF2) (Conti et al., 2005; Figure 1).

Neural lineage differentiation from pluripotent stem cells can be generally achieved under serum-free conditions, which are important for maintaining neural cell cultures. In the past, numerous studies on the differentiation of pluripotent stem cells into nerve cells have been performed, and in this review we focus on representative cases of mouse and human studies (Table 1). The main types of nerve cells that comprise the central nervous system (CNS) are neurons, astrocytes, and oligodendrocytes. A study on the differentiation into each of these cell types and diverse protocols has been previously reported (Cazillis et al., 2006). Retinoic acid (RA) and sonic hedgehog ( $\mathrm{SHH}$ ) were the main factors initially used to drive differentiation of mouse embryonic stem cells (mESCs) into motor neurons (Wichterle et al., 2002). RA has long been known to be a pivotal factor in CNS development and has been used to induce neural differentiation of pluripotent stem cells in vitro (Maden, 2007). Members of the Wnt protein family act as a ligand in the signaling pathways activating proliferation and differentiation of NPCs in the CNS (Kuwabara et al., 2009; Inestrosa and Arenas, 2010). A coculture system was also used to facilitate neural differentiation of mouse (mESCs) and human embryonic stem cells (hESCs). MS5 stromal cells could facilitate neural differentiation induced by the secreted factors, termed stromal cell-derived inducing activity (SDIA) (Bain et al., 1995; Perrier et al., 2004). In neural differentiation of hESCs, the fibroblast growth factor (FGF) functions as both a neural inducing factor and an antagonist to bone morphogenic protein (BMP) (Dhara and Stice, 2008). The still widely used "dual SMAD inhibition" method made use of the Noggin (BMP-antagonist), in conjunction with the SB431542 (TGF $\beta$ inhibitor), for the rapid differentiation of hESCs into a neural rosette structure of the early neurectoderm (Chambers et al., 2009). Noggin has been used in neural induction in various species (Lee et al., 2007), while SB431542 has been used for enhancing neural differentiation during embryoid body (EB) formation (Smith et al., 2008). The combination of these 2 

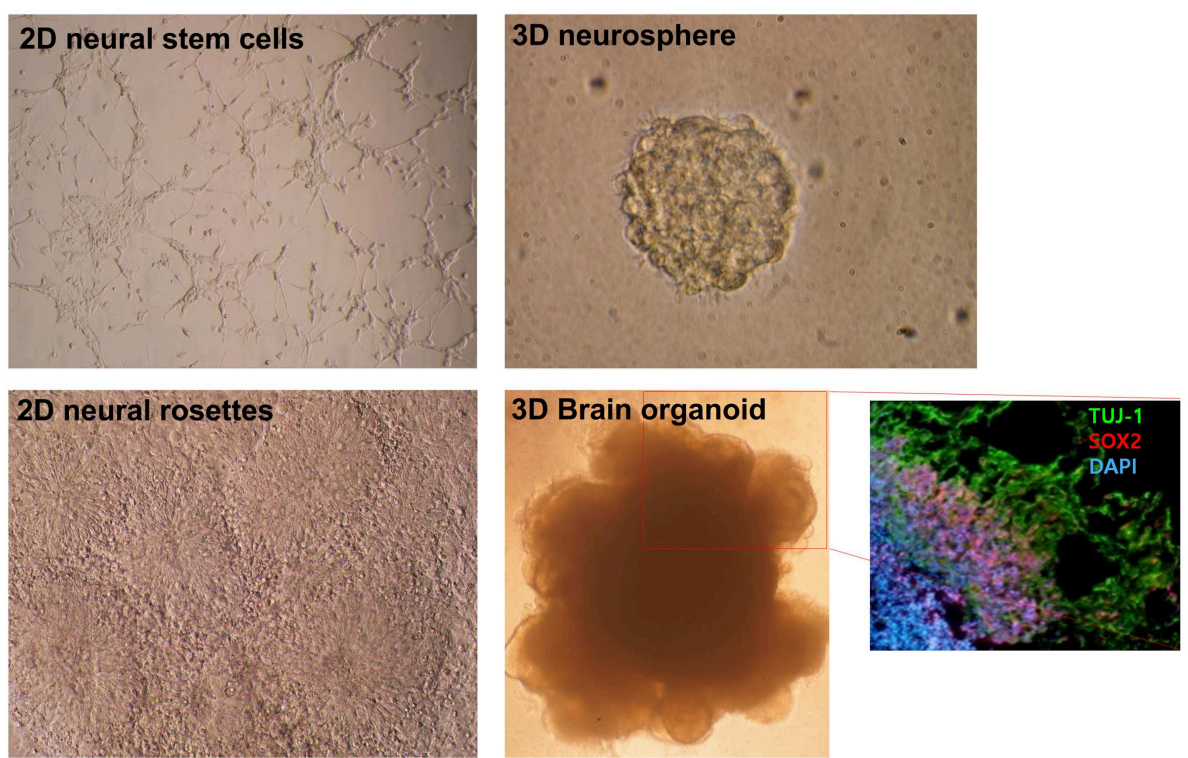

FIGURE 1 | Morphological differences in diverse neural differentiation approaches. The differentiation of pluripotent stem cells into a neural lineage was developed in a stepwise manner: 2D, 3D, and brain organoid. A depiction of the morphologies of growing neural stem cells and neural rosettes in $2 \mathrm{D}$ monolayer cultures. A 3D neurosphere formed with the floating culture technique. Folded brain organoid structure formation after culture embedding in Matrigel and differentiation of pluripoten stem cells. Layer division of early neurons (Tuj-1 positive) and neural progenitors (Sox2 positive) identified by immunocytochemistry. This figure was modified with permission from Stem Cell Biology, published by Life Science Publishing Co.

SMAD signaling inhibitory factors eliminates the need for an intermediate process, such as EB formation or co-culturing with a stromal feeder, and simplifies the neural induction protocol.

Many researchers, including our group, have tried to generate other types of early-stage neural precursors using mouse or human pluripotent stem cells. Mujtaba et al. (1999) isolated ENCAM-positive neuroepithelial stem cells from mESCs, similar to fetal neuroepithelial precursors, that were characterized by long-term self-renewal and differentiation potential into neurons and glial cells. Yan et al. (2013) managed to induce hESCs into an earlier NSC cell type, termed primitive NSCs (pNSCs). These pNSCs showed expression patterns similar to those exhibited by the neural rosette and NSCs in the fetal cortex, as well as differentiation potential to neurons, astrocytes, and oligodendrocytes, in addition to the specialized neuronal subtypes, namely GABAergic, dopaminergic, and motor neurons. We have also, recently, succeeded in deriving pNSCs from human iPSCs in the presence of PD0325901 (MEK inhibitor) and leukemia inhibitory factor (LIF) using simple method that does not require EB formation (Shin et al., 2019). Once NSCs are established, the differentiation potential becomes restricted to neurons and glial cells, regardless of NSC type, except in the case of transdifferentiation-a very rare phenomenon-by which a mature cell directly differentiates into different cell lineages (Wagers and Weissman, 2004).

\section{Advantages and Limitations of 2D Culture Systems}

Because NSCs cultured in monolayers mostly comprise a homogeneous population, the $2 \mathrm{D}$ culture system can be useful for identification of new drugs that are effective for the treatment of neurological diseases (Pollard et al., 2006). Also, differentiation of patient-derived iPSCs into specific neuronal cell types can be a main concept in cell replacement therapies designed to cure neurodegenerative diseases. For example, human pluripotent stem cell-derived neural cells could alleviate symptoms of neurological disorders when transplanted into animal models of neurological diseases (Perrier et al., 2004; Roy et al., 2006; Kriks et al., 2011). Parkinson's disease (PD) is a neurodegenerative disease characterized by motor dysfunction following the death of dopaminergic (DA) neurons in the midbrain (Davie, 2008). Numerous studies have been conducted to differentiate PSCs into DA neurons to facilitate basic research and for the development of new treatments for PD. Co-culture with MS5 stromal cells was found to increase the efficiency of PSC differentiation into neuroepithelial cells (Perrier et al., 2004). Moreover, these authors found that the treatment with fibroblast growth factor 8 (FGF8) and SHH resulted in high production rate of DA neurons after ventralization (Perrier et al., 2004). Roy et al. co-cultured immortalized human fetal astrocytes with hESCs to improve the their differentiation into DA neurons because astrocytes play an important supporting role in neuronal development (Roy et al., 2006). They observed improvement in motor function after transplantation of these DA neurons into a rat PD model. However, DA neuron transplantation can lead to tumor formation due to the proliferation of undifferentiated neural precursors in the differentiation mixture. To overcome this problem, hPSCs were differentiated into DA neurons via the midbrain floor-plate (FP) precursor where DA neurons are made. After transplantation, the proportion of proliferating cells was reduced to $<1 \%$ in FP-derived cell grafts and no neural outgrowth was observed; this outcome is comparable 
TABLE 1 | Neural differentiation approaches in 2D and 3D using stem cells.

\begin{tabular}{|c|c|c|c|c|c|}
\hline Type & Desired cell or tissue type & Approaches & Characteristics & Cell & References \\
\hline \multirow[t]{3}{*}{$2 \mathrm{D}$} & Motor neuron differentiation & - $\mathrm{RA}, \mathrm{SHH}$ treatment & $\begin{array}{l}\text { - Differentiation into spinal progenitor cells and } \\
\text { motor neurons } \\
\text { - Transplantation of RA and SHH treated EBs } \\
\text { into stage 15-17 chick spinal cord }\end{array}$ & mESCs & Wichterle et al., 2002 \\
\hline & $\begin{array}{l}\text { Midbrain DA neuron } \\
\text { differentiation }\end{array}$ & $\begin{array}{l}\text { - Stromal cell co-culture } \\
\text { - Serum-free condition, } \\
\text { LIF removal }\end{array}$ & $\begin{array}{l}\text { - Promoted neural differentiation by SDIA } \\
\text { - Anti-neutralizing effect of BMP4 }\end{array}$ & mESCs & Kawasaki et al., 2000 \\
\hline & $\begin{array}{l}\text { Neural rosette structure } \\
\text { formation } \\
\text { Midbrain DA neuron and motor } \\
\text { neuron differentiation }\end{array}$ & $\begin{array}{l}\text { - Noggin, SB431542 treatment } \\
\text { (Dual-SMAD inhibition) } \\
\text { - For midbrain DA neuron : } \\
\text { Dual-SMAD inhibition (days } \\
\text { 1-5), SHH (days 5-9), BDNF, } \\
\text { ascorbic acid, SHH, and FGF8 } \\
\text { (days 9-12), BDNF, ascorbic } \\
\text { acid, GDNF, TGFb3, and } \\
\text { cAMP (days 12-19) } \\
\text { - For motor neuron : } \\
\text { Dual-SMAD inhibition (days } \\
\text { 1-5), BDNF, ascorbic acid, } \\
\text { SHH, and RT (days 5-11) }\end{array}$ & $\begin{array}{l}\text { - Conversion of more than } 80 \% \text { of hESCs into } \\
\text { neural lineage } \\
\text { - Further differentiation into midbrain DA } \\
\text { neuron and motor neuron }\end{array}$ & hESCs & Chambers et al., 2009 \\
\hline \multirow[t]{3}{*}{$3 \mathrm{D}$ in vitro } & $\begin{array}{l}\text { NSC proliferation } \\
\text { Neural and glial } \\
\text { cells differentiation }\end{array}$ & $\begin{array}{l}\text { - 3D peptide scaffold using } \\
\text { self-assembly proteins (SAPs) }\end{array}$ & $\begin{array}{l}\text { - Survival and proliferation of NSCs in 3D } \\
\text { peptide scaffold } \\
\text { - Differentiation potential to neurons, } \\
\text { astrocytes, and oligodendrocytes }\end{array}$ & mNSCs & Cunha et al., 2011 \\
\hline & $\begin{array}{l}\text { Transdifferentiation into neuronal } \\
\text { or } \\
\text { glial cell types }\end{array}$ & $\begin{array}{l}\text { - 3D scaffold synthesized with } \\
\text { collagen and hyaluronic acid }\end{array}$ & $\begin{array}{l}\text { - Changes in differentiation potency by } \\
\text { scaffold stiffness } \\
\text { - Neuronal differentiation in soft scaffold and } \\
\text { glial differentiation in stiff scaffold }\end{array}$ & hMSCs & Her et al., 2013 \\
\hline & Neuronal differentiation & - 3D artificial nanofiber networks & $\begin{array}{l}\text { - Rapid and selective differentiation into } \\
\text { neurons in artifical nanofiber scaffold }\end{array}$ & mNPCs & Silva et al., 2004 \\
\hline \multirow[t]{2}{*}{$3 \mathrm{D}$ in vivo } & NSC differentiation & - Teratoma formation & $\begin{array}{l}\text { - In vivo isolation of NSCs from miPSCs with } \\
\text { defected differentiation potency in vitro } \\
\text { - Expression of NSC marker Nestin, and Sox2 } \\
\text { - No secondary tumor formation }\end{array}$ & $\begin{array}{l}\text { mESCs, } \\
\text { miPSCs }\end{array}$ & Hong et al., 2016 \\
\hline & NSC differentiation & - Chimera formation & $\begin{array}{l}\text { - Expression of NSC marker Nestin, and Sox2 } \\
\text { - More similar gene expression pattern to } \\
\text { brain-derived NSCs than } \\
\text { in vitro-differentiated NSCs }\end{array}$ & mESCs & Choi et al., 2017 \\
\hline
\end{tabular}


to that observed using conventional rosette-derived cell grafts. The FP-derived DA neurons were successfully engrafted with high survival rates, and ameliorated the phenotypic behavior of animal models of PD (Kriks et al., 2011). In addition, to prevent unwanted cell contamination, Doi et al. sorted cells expressing CORIN, an FP marker, which were used for transplantation. For clinical application, they differentiated PSCs in a xeno-free condition using human laminin (Doi et al., 2014). These studies show that the strategy of $2 \mathrm{D}$ differentiation into a specific cell type can be safely employed in the treatment of neurological diseases. In addition, many researchers are continuously striving to generate better DA neurons that can mimic there in vivo counterparts by using various methods such as co-culture systems, differentiation at specific developmental stages, and using biocompatible materials.

The 2D neural differentiation methods are widely used in the research and preclinical field because they are easy to handle and can utilize various types of NSCs and protocols. Apparently, $2 \mathrm{D}$ differentiation methods can be effective in single cell type differentiation (Garavaglia et al., 2010). However, the actual brain does not consist of only one cell type. Azevedo et al. (2009) suggested that the human brain contains $\sim 86$ billion neurons and 85 billion non-neuronal cells, including glial cells, immune cells, and endothelial cells. It is also known that more than 10 times more non-neuronal cells populate the brain tissues relative to neurons (Carter, 2014). All brain cells are organically connected and interact with each other. Moreover, it should be heeded that organs are not solely composed of cells. The extracellular matrix (ECM) present among cells in tissues plays important roles in cell adhesion, cell-to-cell communication, cellto-ECM interaction, cellular differentiation, proliferation, and migration (Theocharis et al., 2016). Since each of the ECM materials bears different characteristics, by culturing cells on the appropriate ECM materials, the stiffness and elasticity of the resulting tissue can be adjusted accordingly. In the central nervous system (CNS), a large proportion (20-30\%) of the brain is composed of ECM (Nicholson, 2001; Syková and Nicholson, 2008), the composition of which is known to be unique from other organs. Fibrous proteins, such as laminin, fibronectin, and collagen, are relatively scarce in the brain, whereas proteoglycans and glycoproteins are found in abundance. Therefore, this unique ECM composition may reflect the soft properties exhibited by brain tissue (Ruoslahti, 1996; Novak and Kaye, 2000; Bellail et al., 2004; Hopkins et al., 2015). ECM is also known for its influence on neurite extension and neuronal migration (Snow and Letourneau, 1992; Franco and Müller, 2011). In addition to this haptotaxis property, neurite outgrowth and axon guidance concurrently require chemotactic cues such as nerve growth factor (NGF) concentration gradients (Kapur and Shoichet, 2003). Moreover, NSCs cultured in 2D systems progressively lose the ability to differentiate into neuronal cell types. In conclusion, $2 \mathrm{D}$ culture systems cannot mimic the $3 \mathrm{D}$ brain environment where cell types are diverse, cells are supported by ECM, and the temporal and spatial concentration gradients of chemical cues are acting in nervous system development. Thus, to study neural development and physiology more closely reflecting the in vivo brain system, more advanced culture conditions, other than the
$2 \mathrm{D}$ differentiation systems, are required. Thus, the need for $3 \mathrm{D}$ culture methods has gradually emerged.

\section{D DIFFERENTIATION SYSTEMS Creating a 3D Differentiation Environment in vitro}

Interestingly, the first method used for culturing NSCs in vitro was a 3D culture system. Proliferative neural cells isolated from the mouse brain were initially cultured using the neurosphere formation method (Gritti et al., 1996; Figure 1). In order to culture cells in a $3 \mathrm{D}$ system, growing cells were supplied with either ECM material or artificial scaffolding (Hopkins et al., 2015). Levenberg et al. (2003) aimed to engineer tissue-like structures using hESCs grown in $3 \mathrm{D}$ culture systems, such as biodegradable polymer scaffolds [1:1 mixture of poly Llactic acid (PLLA) and poly lactic-co-glycolic acid (PLGA)], and observed that the scaffold can affect cellular differentiation and organization (Nseir et al., 2013). Self-assembling peptides (SAPs) have also been used in creating a $3 \mathrm{D}$ peptide scaffold shown to support proliferation and differentiation of NSCs (Cunha et al., 2011). In a study using 3D scaffold synthesized with collagen and hyaluronic acid, transdifferentiation of human mesenchymal stem cells (hMSCs) to neuronal and glial cells could be efficiently induced by adjusting the stiffness and porosity of the 3D scaffold (Her et al., 2013). In addition, the topological patterns of the scaffold or biomaterials could also affect proliferation and differentiation of NSCs (Qi et al., 2013; Jeong et al., 2015). When mouse NPCs were cultured within $3 \mathrm{D}$ artificial nanofiber networks, neuronal differentiation proceeded rapidly and selectively (Silva et al., 2004). Graphene was suggested to be one of the promising nanomaterials for biological applications, possessing great advantages, such as biocompatibility, flexibility, transparency, and hydrophilicity, and thus when used in culture has led to enhanced neuronal differentiation of hNSCs (Park et al., 2011; Kostarelos and Novoselov, 2014). Although the 3D scaffolds could not support the self-organization of the intrinsic zonal architecture of the tissue, they could provide structural support and enhanced the neural differentiation efficiency. Collectively, the structure, stiffness, porosity, and topological properties of the environment surrounding cells affect not only the characteristics of the cells but also the differentiation direction in the specific lineage (Table 1). In addition to controlling the physical environment, 3D cell culture with control of the hydrodynamic environment has been proposed. Sen et al. suggested that the size of mouse NSC aggregates could be a factor affecting DA neuron differentiation. Therefore, 3D cell culture would allow for obtaining a cell population with uniform size, and for tailoring the size $(<150 \mu \mathrm{m})$ so as to prevent necrosis of the inner region in large cell aggregates (Sen et al., 2001). In another study, functional DA neurons were generated from neuroepithelial stem cells (NESCs) derived from hiPSCs using a phase-guided $3 \mathrm{D}$ cell culture microfluidic bioreactor. These DA neurons expressed tyrosine hydroxylase (TH) with high efficiency ( 91\%) (Moreno et al., 2015). Thus, providing an 
in vitro $3 \mathrm{D}$ environment successfully mimicking the relevant in vivo developmental stage could result in the induction of differentiated cells displaying the morphology, characteristics, and functions of that stage, thus simulating natural development as close as possible.

\section{Neural Differentiation of Pluripotent Stem Cells in a 3D in vivo Environment}

Although as similar as possible to the in vivo-like environment, in vitro environment outside the bodies would not be perfect system. To overcome this, one of the alternative options is to induce differentiation of pluripotent cells directly in the in vivo environment. Recently, we suggested an in vivo neural differentiation method in which pluripotent stem cells were differentiated into NSCs through teratoma formation (Hong et al., 2016; Kim et al., 2017). When pluripotent cells were injected into immunodeficient mice, they formed a teratoma, which is a benign tumor containing cell types of various lineages. Teratoma-isolated Olig2-GFP-positive cells could be established as a pure population of NSCs (Hong et al., 2016). As these established in vivo NSCs did not lead to tumor formation when injected back into immunodeficient mice, they were considered safe and applicable to clinical practice. We also suggested another in vivo differentiation method, where iPSC-derived NSCs were developed in the brain of chimeric mouse (Choi et al., 2017). First, 13.5 dpc chimeric mouse, which are developed from chimeric blastocyst (formed by iPSCs and morula embryos), were used as in vivo NSC forming device. NSCs isolated from the brain of chimeric mouse were closely resembling brain-derived NSCs relative to in vitro-differentiated NSCs, as indicated from examination of their gene expression profiles, indicating that in vivo differentiation methods can better simulate cells in their vivo environment (Table 1). The in vivo NSC derivation system does not require creating an artificial environment, such as ECM, cytokines, and growth factors. However, application of chimeric based NSCs derivation methods in humans seems difficult, because of ethical considerations concerning chimera formations between human and animals and their prohibited status in most countries.

\section{Organotypic Methods}

Along with technical advances in $3 \mathrm{D}$ differentiation methods creating an in vivo-like environment, "organotypic" method techniques were also developed. An organotypic culture is the culture in which the part of the tissue separated from an organ is cultivated in vitro to form organ-like structures. Harrison et al. (1907) cultivated the neural tube of frog embryos in serum using the hanging drop method and observed the obtained neuronal outgrowths. This research demonstrated that cell growth can be possible even if the tissue is removed and grown outside of the body. Thereafter, researchers found that the chick primordia could independently differentiate in vitro, leading to self-formation of CNS tissue in its subsequent in vitro culture (Hoadley, 1924; Waddington and Cohen, 1936). Another group also showed the in vitro self-organization ability of chick and mouse embryo by culturing the dissociated cells acquired from organ rudiments (Moscona and Moscona, 1952; Moscona, 1957). Dissociated cells readily re-aggregated and reconstituted a tissue-like structure. The term "organotypic" was first coined by Reinbold (1954), who observed the ocular differentiation of 3 day chick embryos in vitro. Later on, the brain slice culture of vertebrates and the re-aggregation of the chicken brain cell were also studied (Crain, 1966; Ishii, 1966). Organotypic studies were also conducted in other vertebrates such as rats, mice, and humans (Tansley, 1933a,b; Hogue, 1947; Garber and Moscona, 1972a,b; Eugene et al., 2014; Radonjić et al., 2014). In terms of histology, the organotypic culture method can be helpful in observing cell types, relationships, and communication between cells in a particular tissue and has provided the basis for the ongoing organoid research (Shamir and Ewald, 2014; Humpel, 2015). For clinical application, a biopsy-capable tissue may be able to generate organoids based on organotypic culture; however, for some tissue types such as the brain, 3D organoid differentiation will need to be induced using the patient's own iPSCs.

\section{Self-Assembly Potential of Pluripotent Stem Cells}

Prior to the current organoid research, pioneering work in the field had been conducted by the Sasai group (Figure 2). The group established a suspension culture, termed SFEB (serum-free floating culture of embryoid body-like aggregates), that minimized extraneous signals (Watanabe et al., 2005). ESCs cultured in this chemically defined medium without serum were differentiated into neuroectodermal cells, in turn providing cortical progenitors and functional neurons. Notably, they observed that $3 \mathrm{D}$ aggregates could mimic embryonic corticogenesis and suggested a self-organization ability of cells during differentiation of hESCs (Eiraku et al., 2008; Mariani et al., 2012). By using this method, the group generated an earlystage self-organized cortical neuroepithelium with immature properties at first, but finally managed to generate more mature hESC-derived cortical tissue that recapitulated secondtrimester neocorticogenesis. The generated multi-layered cortical tissue was arranged in the appropriate order, in an insideout pattern, which is characteristic of the cerebral cortex, and contained an oSVZ layer and outer radial glial cells (oRGCs) which only exist in primates (Kadoshima et al., 2013). The same group also generated an optic-cup structure containing retinal tissue by using 3D differentiation of mESCs and hESCs (Eiraku et al., 2011; Eiraku and Sasai, 2012; Nakano et al., 2012). They suggested that the spontaneous formation of the hemispherical structure in the simple $3 \mathrm{D}$ culture might be attributable to the intrinsic self-organizing program of the ESC-derived epithelial structure. This method was later used in generating an eye organoid and identifying the importance of R-spondin in neuroretina differentiation (Takata et al., 2017a). The self-organizing properties of ESC-derived tissues were applicable to generation of other brain regions such as functional adenohypophysis tissue, telencephalic tissue, and polarized cerebellar tissue from hESCs (Suga et al., 2011; Muguruma et al., 2015; Sakaguchi et al., 2015). 


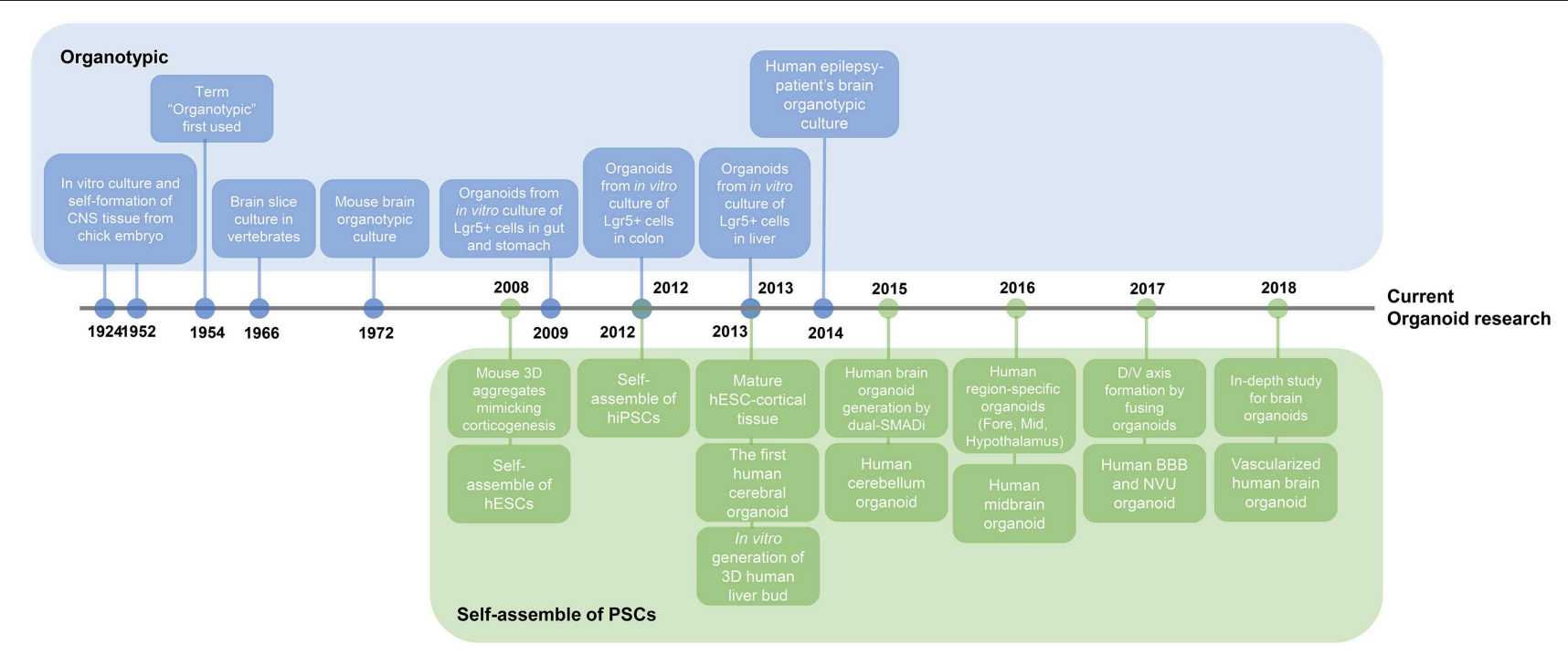

FIGURE 2 | Timeline of key findings in current brain organoid research. Research on organoids began with two studies. Organotypic, a culture method that divides organs or tissues into smaller units and then re-builds them in vitro, has long been used for the external growth of tissues. This figure illustrates the presence of adult stem cells in different organs, leading to adult stem cell-based organoid study. On a separate note, the basis for the study of brain organoids has been the plethora of studies of self-organizing pluripotent stem cells. Nowadays, research on brain organoids has surpassed the stage of creating region-specific organoids to better mimic the in vivo brain properties, such as vascularization and axis formation.

\section{BRAIN ORGANOID}

\section{Beginning and Advances in Organoid Research}

The word organoid is a compound of the stem words "organ" and "-oid" and refers to the mini organ-like 3D cellular aggregates that resemble actual organ tissues. Cultured organoids include not only tissue-specific cell types but also stem cells that carry self-renewal properties. Hence, organoids can grow by themselves over a long period of time, which is the feature that distinguishes them the most from spheroids. Importantly, organoids contain a variety of cell types that are not merely randomly arranged, but rather preserve the unique intrinsic organization of the desired organ and can mimic in vivo organs. Thus, they can recapitulate some functions and developmental details of the specific organ. By culturing organoids that are selforganized in vitro, cell-cell interactions between diverse cell types in an organ can be observed. With respect to clinical research and application, organoids have an advantage over 2D culture systems because long-term drug response can be simultaneously evaluated in various cell types, which can accelerate the process of drug discovery.

Initially, organoid research was essentially based on organotypic culture methods (Figure 2). Isolated tissues were used to form aggregates and mini-organ-like structures. In 2009, the Clevers group discovered that leucine-rich repeat-containing G-protein coupled receptor 5 (LGR5) positive gut stem cells could be self-assembled into cellular aggregates and then further grow and form gut epithelial structure in vitro termed cryptvillus organoid. When organoids were dissociated into single cells and re-cultured, the dissociated cells could regenerate new organoids, indicating that adult stem cells in organoid are able to continuously organize new tissues (Sato et al., 2009). LGR5, a WNT target gene, is expressed in multipotent adult stem cells in diverse organs, such as intestine, kidneys, stomach, ears, and hair follicles. Hence, researchers have used Lgr5 as a biomarker of stem cells able to organize and further establish organoids in the stomach, colon, and liver (Sato et al., 2009; Yui et al., 2012; Huch et al., 2013).

An even more promising approach is the generation of organoids using pluripotent stem cells. By using human iPSCs, researchers could avoid the hassle of collecting tissues from human bodies. Acquisition of vascularized and functional human iPSC-derived liver buds (iPSC-LBs) has been described by the Taniguchi group. The group co-cultured human iPSC-derived hepatic cells (iPSC-HEs) with hMSCs and human umbilical vein endothelial cells (HUVECs) based on the idea that organs do not consist of single lineage cells but groups of several tissues. As a result, vascularized and mature liver buds were established by transplantation into immunodeficient mice (Takebe et al., 2013, 2014).

\section{Brain Organoid}

In the case of the brain, and due to the difficulties associated with obtaining tissue from human bodies, brain organoid studies were conducted mainly by using differentiated pluripotent stem cells rather than performing organotypic methods (Figure 2). The first attempt in obtaining a brain organoid was reported in 2013 by the Knoblich group (Lancaster et al., 2013). The group developed a human PSC-derived cerebral organoid culture system by using a Matrigel matrix and a spinning bioreactor. Briefly, the group embedded neural-lineage committed embryoid bodies (EBs) in Matrigel, an artificial ECM, and spin cultured them in bioreactors, enabling EBs to be cultured long-term 
and mini-brain structure to be form. Today, This method has become one of the standard protocols widely used to generate human brain organoids. This protocol is considered indirect or intrinsic, as it relies on the differentiation potential and the cells' self-organizing program without giving any inductive signals (Lancaster et al., 2013; Lancaster and Knoblich, 2014). This indirect protocol drives the cell fate of the brain organoid into a biased forebrain identity. Nonetheless, the organoid contains various other brain regions, such as the retina, mDA neurons, and even non-ectodermal cells. This great complexity, stochasticity, and self-organization guide the interactions between cells and further promote the maturation of brain organoids (Quadrato et al., 2017). However, this indirect method may produce unwanted regions in the organoid and the pattern of organoid formation is inconsistent in each experiment.

Recently, directed differentiation protocols have also arisen to increase homogeneity of cells that constitute the brain organoid. The "dual-SMAD inhibition" method used for efficient derivation of neurons from pluripotent stem cells, was applied for brain organoid generation (Chambers et al., 2009). This method directed pluripotent stem cells into the neural lineage and inhibited differentiation into other lineages while pre-patterning embryoid bodies. As such, this reduced tissue heterogeneity and increased differentiation efficiency of the neural lineage (Paşca et al., 2015; Qian et al., 2016). After the neural identity of the embryoid body was established using the "dual-SMAD inhibition" method, forebrain organoids were generated in miniaturized spinning bioreactors. In this protocol, the shape and size of the generated forebrain organoids were more consistent relative to those derived by the intrinsic method. Furthermore, the team observed the presence of oRGCs and a well-developed oSVZ-like layer, a specific structure of the developing primate cerebral cortex, in their forebrain organoids. They identified the presence of six cortex layers and subsequent neuronal subtypes in their organoids and observed the growing and maturing cortex through the comparison of organoids of various developmental stages (Qian et al., 2016). Another group also tried to generate midbrain-specific organoids by pre-inducing iPSCs into neuroepithelial stem cells, which are in a more faterestricted state than pluripotent cells (Monzel et al., 2017). The group produced brain organoids that were highly specific to the midbrain, containing DA neurons with a high degree of neurite myelination by oligodendrocytes. Collectively, the assortment and developmental potential of the starting population of cells directed toward generation of brain organoid could dictate the patterns of the resulting organoids. Since both indirect and direct organoid formation methods have advantages and disadvantages, use of each should be based according to the purpose of the experiment.

\section{In-depth Analysis of Brain Organoids}

Some of the questions arising include, what kind of cells typically reside in a brain organoid, and how similar are brain organoids to the real brain? The brain not only consists of several distinct parts, but each of these parts is composed of and is characterized by diverse sets of cell types. Neurons and glial cells are the major cell types present in the brain, along with endothelial and mesenchymal cells. A large-scale singlecell sequencing of human whole brain organoids has revealed their cellular composition (Quadrato et al., 2017). Six-monthold brain organoids consisted mainly of 7 clusters, one of which was the mesodermal lineage cells. The other 6 clusters were as follows: astroglia, DA neurons, forebrain, retina, neuroepithelial cells, and proliferative progenitors. It was revealed that 3-monthold brain organoids lacked some cell types, such as putative callosal projection neurons, muller glia, and bipolar cells that existed in 6-month-old brain organoids. Moreover, astroglial cells were in a more immature state compared to those in the 6month-old brain organoids (Quadrato et al., 2017). Recently, the single-cell transcriptome and chromatin accessibility of primate cerebral organoids were investigated (Kanton et al., 2019). Single-cell RNA sequencing analysis revealed that human cerebral organoids generated by an indirect method contained the forebrain, midbrain, hindbrain, retinal cells, and NPCs in the early stage. At the later stage, astrocytes as well as neuronal cell types appeared. Interestingly, human cerebral organoids have been found to develop more slowly than those of chimpanzees and macaques, which corresponds to the difference observed in actual brain development between humans and non-human primates (Kanton et al., 2019). Therefore, these results are indicative of the fact that organoids grown in vitro are maturing over time. This notion gives more reason for improving the culture environment when it comes to long-term cultures. Although brain organoids contain neurons and glial cells, their ratio does not usually match the ratio observed in an actual brain. Glial cells play several roles in supporting neurons, and are involved in all aspects of brain function, including nervous system development, nutrition and oxygen supply, elimination of pathogens, as well as synaptic connections. During development, glial cells originate from the radial glial cells, which help in the migration of neurons until 21 weeks gestation in humans, and function as stem cells that ultimately differentiate into neurons and glial cells (Kadhim et al., 1988). Despite the diverse types of neurons investigated in organoid studies, there has been relatively little research performed on glial cells in the CNS and brain organoids. As gliogenesis begins relatively late compared to the development of neurons during development, it might be difficult to identify diverse types of mature glial cells in brain organoids. An in-depth analysis of brain organoids by RNA sequencing revealed that 6-month-old brain organoids contained mature astrocytes (Quadrato et al., 2017). Similarly, another group observed that 8-month-old organoids contained oligodendrocyte progenitors (Renner et al., 2017). Sloan et al. (2017) cultured human cortical spheroids (hCSs) for up to 590 days and conducted single-cell RNA sequencing at multiple time points, which revealed the presence of HepaCAMpositive astrocytes in the CSs at 100 days after culture. These HepaCAM-positive astrocytes showed the morphological and functional properties of mature astrocytes, such as modulation of calcium signaling, synapse formation in neurons, and phagocytic capacity. A study on the differentiation of oligodendrocytes, one of the glial cell types that function in the myelinating neurons, was conducted using the $3 \mathrm{D}$ spheroid culture method. To induce oligocortical spheroids from human PSCs, the spheroids 
were cultured with oligodendrocyte differentiation medium and growth factors, including platelet-derived growth factor AA (PDGF-AA), insulin-like growth factor 1 (IGF-1), and thyroid hormone (T3). Myelination of neurons was observed in 20week-old oligocortical spheroids, while a maturated state was exhibited in 30-week-old spheroids (Madhavan et al., 2018). Another group that generated "oligodendrocyte spheroids" from human PSCs in a similar manner, identified that that the myelinating oligodendrocytes in 127-day-old spheroids exhibited characteristics similar to those of mature primary oligodendrocytes (Marton et al., 2019). According to the RNAsequencing results, the spheroids contained oligodendrocytes, neurons, astrocytes, microglia, and endothelial cells. Microglia and endothelial cells are typically hard to find in brain organoids because they are formed from different germ layers and not from the ectoderm (Fatehullah et al., 2016; Dutta and Clevers, 2017). However, a recent report suggested that early-stage cerebral organoids contain microglia that develop from mesenchymal progenitors (Ormel et al., 2018).

In addition to the existence of the oSVZ layer, the presence of brain wrinkles distinguishes the human from the mouse brain. There are numerous wrinkles in the brain of large mammals, such as humans, which were thought to be a measure of intelligence. In fact, wrinkles in the brain widen the entire surface area of the brain, allowing for the processing of more information. However, the human brain folding mechanism was unclear, as it was difficult to observe it live in vitro. By using brain organoid technology, a research group was able to observe and analyze the folding process of developing brain organoids. Based on data suggesting that PTEN-AKT signaling controls the cortical formation in the human brain, a study aimed to observe the folding of the cerebral organoid carrying a phosphatase and tensin homolog (PTEN) deletion was conducted (Li et al., 2017). The PTEN mutant brain organoid showed an AKT signalinginduced increase in progenitor proliferation, thereby delaying differentiation and expanding the ventricular zone (VZ) and SVZ regions. Consecutively, the degree of surface folding increased and the surface area widened. Recently, researchers combined physics and biology approaches to analyze the mechanism that drive folding progression and maintenance by using an on-chip approach (Karzbrun et al., 2018).

\section{Region-Specific Brain Organoids}

In addition to the study of whole brain organoids, region-specific brain organoids have been studied, including forebrain, hindbrain, hippocampus, and hypothalamus organoids (Kadoshima et al., 2013; Muguruma et al., 2015; Paşca et al., 2015; Sakaguchi et al., 2015; Ozone et al., 2016; Qian et al., 2016; Shirai et al., 2016). As the brain consists of various regions, researchers have continued to create region-specific brain organoids. Anatomically, the developing brain can be divided in three main regions: forebrain, midbrain, and hindbrain. The forebrain is the largest area of the brain and consists of the cerebrum, thalamus, and hypothalamus. Midbrain acts as a connection between the forebrain and hindbrain and along with hindbrain forms the brainstem. The hindbrain consists of the cerebellum, pons, medulla, and is connected to the spinal cord. In the absence of forced inducing signals, most brain organoids get a forebrain identity by default (Lancaster et al., 2013). To specify hippocampal tissue from hESCs, organoid had to be regulated by BMP and WNT signaling. First, the choroid flexus-like tissue was created by adding a WNT inhibitor (CHIR99021) and BMP4, and then the adjacent tissue medial pallium, a precursor of hippocampus, was generated by reducing the exposure time to these two factors. This medial pallium-like tissue matured into a hippocampal primordium-like tissue expressing markers, such as neuropillin2 (NRP2), and zinc finger and BTB domain containing 20 (ZBTB20). Because of the difficulties associated with long term cultures, tissues were dissociated and attached for an additional $17 \mathrm{wk}$. After that, hippocampal pyramidal- and granule-like neurons, as well as astrocyte-like cells were identified in the growing aggregates (Sakaguchi et al., 2015). For the generation of hypothalamus specific organoids, pre-patterned by "dual SMAD inhibition" EBs were differentiated into hypothalamic lineages by adding WNT, $\mathrm{SHH}$, and purmorphamine (PMA) followed by a maturation stage with added FGF2 and ciliary neurotropic factor (CNTF). Formed 40-d-old hypothalamic organoids expressed peptidergic neuronal markers and orthopedia (OTP), a marker of the developing hypothalamus (Qian et al., 2016). Midbrain and hindbrain organoids can also be generated by regulating proper signaling pathways required for the developmental process of each region based on research findings from previous brain development and 2D differentiation studies. FGF8 is known to be expressed in the mid-hindbrain boundary (MHB) and plays an important role in the posterior brain region specification while suppressing differentiation into the forebrain lineage (Crossley et al., 1996). By adding FGF8 and SHH as midbrain patterning factors, 3D midbrain-like organoids with functional $\mathrm{mDA}$ neurons were successfully generated. These midbrain organoids produced neuromelanin-like granules, which are expressed in the substantia nigra of the midbrain after maturation with several factors (brain-derived neurotrophic factor (BDNF), glial cell line-derived neurotrophic factor (GDNF), ascorbic acid, and db-cAMP) (Jo et al., 2016). Another group also used FGF8, SHH agonists, SMAD inhibitors, and a glycogen synthase kinase 3 beta (GSK3 $\beta$ ) inhibitor to generate midbrain-specific organoids (Qian et al., 2016). Midbrain organoids could also be generated from NESCs differentiated from pluripotent stem cells (Monzel et al., 2017). Cerebellum, which controls motor function, is a major part of the hindbrain. Polarized cerebellar tissue could be generated with the caudalizing factor FGF2 at an initial stage followed by the sequential addition of fibroblast growth factor 19 (FGF19) and stromal cell-derived factor 1 (SDF1). This cerebellar tissue had electrophysiologically functional Purkinje neuron cells expressing the maturation markers Purkinje cell protein 2 (L7 or PCP2), Calbindin 1 (CALB1), and LIM homeobox 5 (LHX5). Notably, this hindbrain neural-tube-like tissue gained dorsoventral polarity spontaneously, suggesting FGF19 as the ventralizing factor, since FGF19 treatment led to the increased expression of the ventral markers (Muguruma et al., 2015; Muguruma, 2017). To our knowledge, organoids of other hindbrain structures, such as medulla and pons-specific organoids, have yet to be established. 
Region-specific brain organoids are deemed effective in the study of the regional function of local cells, whereas wholebrain organoids are considered much more effective for the systemic study of the overall activity and interactions in the whole of brain. To mimic the actual brain structure, researchers physically combined the individual region-specific organoids after generating each of the desired specific organoids. Organizing the dorsal-ventral axis of the forebrain was performed by 3 individual groups almost at the same time (Bagley et al., 2017; Birey et al., 2017; Xiang et al., 2017). Each group generated dorsal and ventral forebrain organoids separately and combined them to form a whole forebrain, thereby revealing the interneuron migration occurring between the 2 organoids. So as to obtain medial ganglionic eminence (MGE)-like organoids, which correspond to the ventral region, one of the groups, applied a SHH and PMA treatment (Xiang et al., 2017). The 2 other groups used the SAG SHH agonist and the IWP-2 WNT inhibitor as ventral patterning factors (Bagley et al., 2017; Birey et al., 2017). More specifically, Birey et al. (2017) generated a forebrain organoid that could be used as a Timothy syndrome model system, by assembling two individual forebrain spheroids and found that in Timothy syndrome, a neurodevelopmental disorder, interneuron migration between the dorsal and ventral forebrain was defective.

\section{Vascularization of Brain Organoid}

As the organoids grow bigger over long-term culture, their inner area suffers from a lack of oxygen and nutrient supply. In the body, blood vessels are distributed inside the brain functioning as gas exchange, nutrient exchange, and waste discharge routes, but brain organoids lack these vessel-like structures. Generating brain blood vessels endogenously during the process of brain organoid generation is difficult with the current protocols, but it will be possible in the future to either co-culture cells that can become blood vessels or transplant differentiated blood vessels into brain organoids. Unlike other organs, the cerebrovascular system is characterized by the bloodbrain-barrier (BBB) which mainly consists of brain microvascular endothelial cells (BMECs). A number of studies previously conducted aimed to differentiate hPSCs into BMECs. These hPSC-BMECs were sufficiently representative of the endothelial cells present in human $\mathrm{BBB}$ and were able to model the $\mathrm{BBB}$ phenotype when co-cultured with astrocytes and pericytes (Lippmann et al., 2012; Katt et al., 2016; Hollmann et al., 2017; Qian et al., 2017, 2019; Ribecco-Lutkiewicz et al., 2018). Recently, researchers established a $\mathrm{BBB}$ model organoid, a self-assembled spheroid by co-culturing hBMECs or human cerebrovascular microendothelial cells (hCMECs) with astrocytes and pericytes. This BBB organoid was used for testing the permeability of foreign molecules, as it had the ability to regulate transportation of external molecules, which is the most important function of actual BBB (Cho et al., 2017; Bergmann et al., 2018). A vessel composed of BMECs, along with the surrounding astrocytes, pericytes, microglia, ECMs, and neurons are combined to form the basic unit of the brain, the neurovascular unit (NVU). The approach to $3 \mathrm{D}$ modeling of the NVU was similarly performed in vitro, using a microfluidic system and ECM gels for coculturing NSCs, BMECs, and MSCs so as to simultaneously induce neurogenesis and angiogenesis (Uwamori et al., 2017). Mansour et al. (2018) reported on obtaining in vivo vascularized brain organoids via transplantation into a mouse brain. It should be noted that the extended blood vessels were those of the host and not originating from the transplanted brain organoid. Nevertheless, the meaningful point of this finding is that when they were transplanted, brain organoids tried to survive by sharing the blood vessels of the host. Another group created vascularized brain organoids by embedding the brain organoids and endothelial cells differentiated from iPSCs isolated from the patient into a Matrigel (Pham et al., 2018). In addition, we propose a method for vascularizing brain organoids using hBMECs and culture materials (Figure 3). There are two potentially feasible approaches to vascularize organoids. hBMECs could undergo angiogenesis either inside or outside of the brain organoid. Vascular endothelial growth factor (VEGF) from the cells in organoids may induce the vascularization and migration of hBMECs (Radisavljevic et al., 2000). Vascularization in brain organoids will be important for the long-term culture of largersized organoids and is also important for ensuring their similarity to the native brain structure. Importantly, it has shown great promise in cerebrovascular disease research and drug testing.

\section{Disease Modeling}

Beyond basic research on the brain, another goal of the research using organoids may be toward improving human health through the study of diseases. Brain organoid research has facilitated the study of brain diseases by enabling the exploration of the human brain that has not been easily accessible. When combined with research on iPSCs, customized studies can be conducted by establishing patient-specific disease models (Table 2). Microcephaly was the first disease investigated by the Knoblich group using the brain organoid. The group tried to form a brain organoid using skin fibroblast-derived iPSCs from microcephaly patients. However, because microcephaly iPSCs displayed problems in the EB formation stage, the starting point of brain organoid formation, they modified the protocol by increasing the starting cell number. The researchers modified the protocol by increasing the starting cell number. Microcephaly iPSC-derived brain organoids showed a reduced overall size compared to normal brain organoids, especially in the neural progenitor regions due to premature differentiation (Lancaster et al., 2013). Recently, another group attempted to identify the cause of microcephaly in newborns following infection of pregnant women with the ZIKA virus (Garcez et al., 2016). The team infected 3 separate models, a 2D monolayer culture of iPSC-derived NSCs, a neurosphere, and a brain organoid with the ZIKA virus. As a result, the iPSC-derived NSCs and neurosphere models exhibited cell death and disruption, and the brain organoid model showed a $40 \%$ decrease in size relative to normal. ZIKA virus preferentially targeted NPCs, therefore early stage organoids suffered the most critical damages, including a reduction in overall size and VZ layer thickness (Qian et al., 2016). The reason for the decrease in NPC pools was that ZIKA virus triggered premature differentiation of NPCs, similar to 


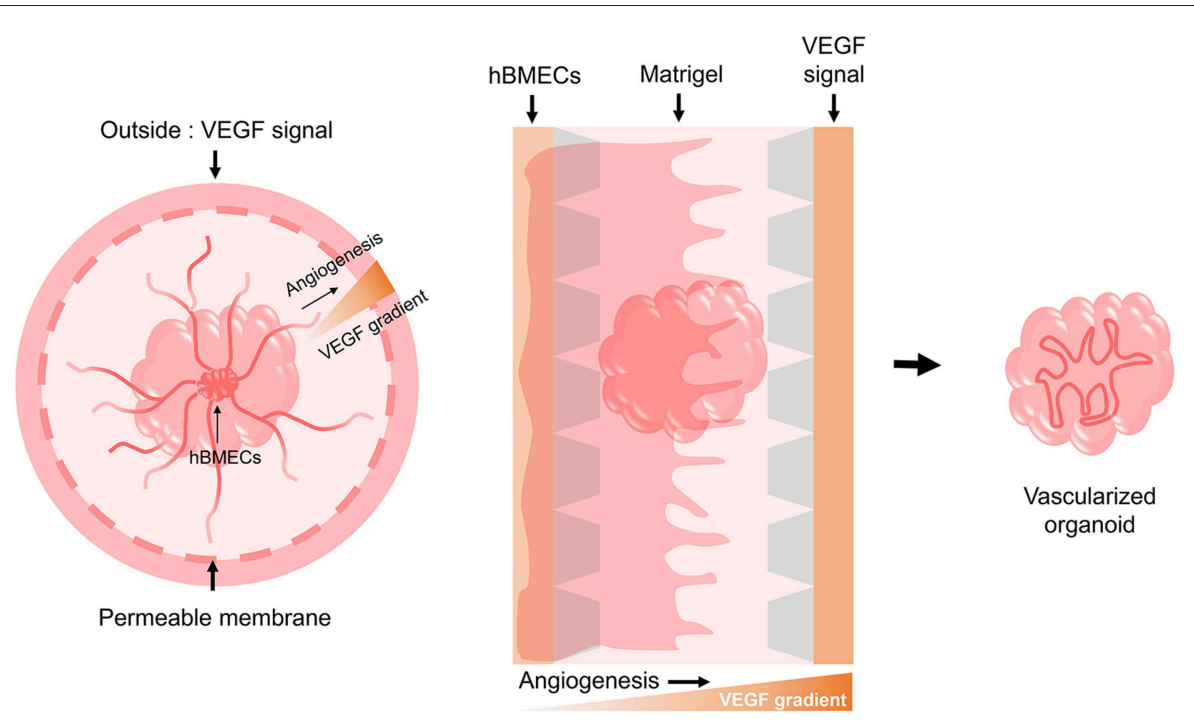

FIGURE 3 | Possible models for the vascularization of brain organoids. Based on the need for a VEGF signal during the angiogenesis of hBMECs that make up the human BBB, we suggest two potential models using culture devices. One model involves implanting the hBMECs inside the brain organoid and then providing the VEGF signal externally through a permeable cell culture dish to induce angiogenesis as it penetrates the brain organoid. The other model involves creating a gradient by providing the VEGF signal to the opposite side of hBMECs using a 3D cell culture chip device, thereby allowing angiogenesis to occur by penetrating the brain organoid.

what was observed in the case of the brain organoids derived from hereditary microcephaly patients (Lancaster et al., 2013; Gabriel et al., 2017). Activation of the Toll-like receptor 3 (TLR3) by ZIKA virus infection was presented as the cause of cell dysregulation and apoptosis, further reinforced by the finding that when TLR3 was inhibited the phenotype was attenuated (Dang et al., 2016). The Miller-Dieker syndrome (MDS) is characterized by abnormally smooth surface and lack of folding structure in the brain (lissencephaly), as well as microcephaly (Dobyns et al., 1983). Due to this odd morphological phenotype, it would be easy to observe its phenotype using a brain organoid. Two groups generated iPSCs-derived cerebral organoids from MDS patients and both of them observed an overall size reduction in the MDS model organoid compared to the wildtype organoid. One study revealed increased apoptosis of NESCs and decreased migration of neurons in the MDS model organoid. The researchers focused on oRGCs and noticed that in the MDS model organoid oRGCs exhibited prolonged mitosis periods (Bershteyn et al., 2017). The second group observed the ventricular zone radial glia cells (vRGCs). In that study, the division plane of vRGCs in the MDS model organoid was changed from symmetric to asymmetric and additionally, the microtubule network organization of these cells was also altered (Iefremova et al., 2017).

Rett syndrome (RTT) is a neurodevelopmental disease caused by mutations in the X-linked gene methyl-CpG-binding protein 2 (MECP2) (Amir et al., 1999). The effects of MECP2 deficiency in neural development were investigated in both $2 \mathrm{D}$ monolayer and $3 \mathrm{D}$ brain organoid cultures using RTT patient-derived iPSCs. Along with the result of monolayer differentiation, the RTT model organoid contained an increased number of proliferating NPCs, which resulted in an expanded VZ area, while neurogenesis and neural maturation were impaired (Mellios et al., 2018). Regarding neuropsychiatric diseases, a schizophrenia model organoid exhibited increased proliferation and abnormal premature migration of NPCs, resulting in malformation of the cortical region (Stachowiak et al., 2017).

Alzheimer's disease (AD) is a progressive, age-related neurodegenerative disease causing dementia in late-life (Hardy and Selkoe, 2002). Previously, efforts had been made to model $\mathrm{AD}$ through $2 \mathrm{D}$ cultures, but there were issues related with the absence of extracellular protein and the diffusion of amyloid- $\beta$ in the culture medium (D'avanzo et al., 2015). Therefore, researchers applied 3D culture methods to study $\mathrm{AD}$ by either Matrigel embedded cultures of hNPCs overexpressing multiple $\mathrm{AD}$ mutations, or scaffold-free brain organoid differentiation of iPSCs from AD patients. Both models revealed the common pathology of $\mathrm{AD}$ : amyloid- $\beta$ deposition and hyperphosphorylation of tau protein. These symptoms were attenuated by $\beta$ - or $\gamma$-secretase inhibitor treatment (Choi et al., 2014; Raja et al., 2016). Interestingly, in the scaffold-free 3D model, amyloid- $\beta$ deposition and hyperphosphorylation of tau protein occurred sequentially as the organoid aged over time (Raja et al., 2016). Another study used iPSCs from AD and Down syndrome (DS) patients to form a cerebral organoid, which also showed the two main pathologies mentioned above (Gonzalez et al., 2018). Parkinson's disease (PD), along with $\mathrm{AD}$, is one of the common neurodegenerative diseases. The pathological feature of $\mathrm{PD}$ is degeneration of the $\mathrm{mDA}$ neurons, resulting in motor function issues. In addition to the suggestion of PD modeling using a midbrain organoid (Jo et al., 2016), sporadic PD model midbrain organoids from leucine-rich repeat kinase 2 
TABLE 2 | Disease modeling approach using brain organoids.

\begin{tabular}{|c|c|c|c|c|}
\hline Disease model & Type of organoid & Phenotypes & Cell & References \\
\hline \multicolumn{5}{|c|}{ Neurodevelopmental disease } \\
\hline Microcephaly & Forebrain organoid & $\begin{array}{l}\text { - Reduction in overall size of organoid } \\
\text { - Premature differentiation of NPCs }\end{array}$ & hiPSCs & Lancaster et al., 2013 \\
\hline \multirow[t]{4}{*}{$\begin{array}{l}\text { Microcephaly (caused by } \\
\text { ZIKA virus) }\end{array}$} & $\begin{array}{l}\text { NPCs, Neurosphere brain } \\
\text { organoid }\end{array}$ & $\begin{array}{l}\text { - Reduction in overall size of organoid } \\
\text { - Cell disruption and death in neurospheres }\end{array}$ & hiPSCs & Garcez et al., 2016 \\
\hline & Forebrain organoid & $\begin{array}{l}\text { - Preferentially infection in NPCs at the early stage } \\
\text { organoid } \\
\text { - Reduction in overall size and VZ layer thickness }\end{array}$ & hiPSCs & Qian et al., 2016 \\
\hline & NPCs brain organoid & $\begin{array}{l}\text { - Premature differentiation of NPCs } \\
\text { - Reduction in VZ and cortical layer } \\
\text { - Defect in centrosomal structure of NPCs }\end{array}$ & hiPSCs & Gabriel et al., 2017 \\
\hline & Cerebral organoid & $\begin{array}{l}\text { - Activation of Toll-like receptor } 3 \text { (TLR3) after ZIKA } \\
\text { infection } \\
\text { - Dysregulation of neurogenesis genes } \\
\text { - Reduction in overall size and neuroepithelium }\end{array}$ & hESCs & Dang et al., 2016 \\
\hline $\begin{array}{l}\text { Lissencephaly (Miller-Dieker } \\
\text { syndrome) }\end{array}$ & Forebrain organoid & $\begin{array}{l}\text { - Reduction in overall size of organoid } \\
\text { - Division plane of vRGCs was changed from } \\
\text { symmetric to asymmetric } \\
\text { - Altered microtubule network organization } \\
\text { of vRGCs }\end{array}$ & hiPSCs & lefremova et al., 2017 \\
\hline Rett syndrome (RTT) & Cerebral organoid & $\begin{array}{l}\text { - Increased number of proliferating NPCs } \\
\text { - Expanded VZ area } \\
\text { - Impaired neurogenesis and maturation }\end{array}$ & hiPSCs & Mellios et al., 2018 \\
\hline \multicolumn{5}{|l|}{ Neuropsychiatric disease } \\
\hline Schizophrenia & Cerebral organoid & $\begin{array}{l}\text { - Increased NPC proliferation } \\
\text { - Abnormal premature migration of NPCs } \\
\text { - Malformation in cortical region }\end{array}$ & hiPSCs & Stachowiak et al., 2017 \\
\hline & Cerebral organoid & $\begin{array}{l}\text { - Amyloid- } \beta \text { deposition } \\
\text { - Hyperphosphorylation of tau protein } \\
\text { - Similar phenotypes of Down syndrome(DS) } \\
\text { brain organoid }\end{array}$ & hiPSCs & Gonzalez et al., 2018 \\
\hline Parkinson's disease (PD) & $\begin{array}{l}\text { Midbrain organoid (Sporadic PD } \\
\text { model with LRRK2-muatation) }\end{array}$ & $\begin{array}{l}\text { - Decreased DA neuron and mature neuron } \\
\text { - Abnormal localization of } \alpha \text {-synuclein } \\
\text { - Suggesting a relationship between TXNIP gene } \\
\text { and sporadic PD }\end{array}$ & hiPSCs & Kim et al., 2019 \\
\hline
\end{tabular}

(LRRK2)-mutant iPSCs were recently studied (Kim et al., 2019). This model could reproduce the pathology of PD, demonstrating decreased DA neuron and mature neuron marker expression and abnormal localization of $\alpha$-synuclein. Furthermore, the group observed upregulation of thioredoxin-interacting protein (TXNIP) expression in the PD model midbrain organoids, whereas when TXNIP was inhibited in knockdown experiments, $\alpha$-synuclein aggregation was decreased, suggesting a relationship between the TXNIP gene and sporadic PD.

\section{CONCLUSION AND FUTURE PERSPECTIVES}

Recent neural differentiation research has focused on the best methods for mimicking the brain tissue-like structure, leading to the development of organoid technology. Despite the remarkable developments in brain organoid research, there remain limitations that require to be overcome. Because the composition of the brain involves complex connections between 
multiple parts, and region-specific distribution of cells, imitating the structure and function of the whole brain poses an obvious difficulty in brain research. Organoids that simulate the actual cell type ratios and region-specific distribution of cells may be obtained by formulating the optimal cell composition through $3 \mathrm{D}$ printing technology. Anterior-posterior and dorsal-ventral axis formation could be induced by establishing concentration gradients of a patterning factor through a microfluidic system or releasable materials. Despite several studies on dorsal-ventral axis formation, all of these attempts focused on generating each part of the brain organoid separately, and then physically merged them together. However, this method was found to be insufficient for observing the complex composition of the brain (Bagley et al., 2017; Birey et al., 2017; Xiang et al., 2017). An alternative approach to mimic the brain axis would be to create concentration gradients of signaling molecules, which might result in an environment similar to that of the developing brain during brain organoid formation. Use of a microfluidic system is one option to produce such spatiotemporal concentration gradients by which complex chemical gradients can be effectively controlled. Park et al. (2009) differentiated hESCs into NPCs by using a microfluidic system to create a gradient of SHH, FGF8, and BMP4. In addition, a signal gradient could be achieved using patterning beads (Kelava and Lancaster, 2016); anterior-posterior axis patterning might be induced by placing the anterior and posterior patterning beads at opposite ends of the organoids. When Takata et al. embedded FGF inhibitor-soaked beads with mESC-derived aggregates, the part adjacent to the beads that received a relatively poor FGF signal developed into the rostral neuroectoderm (Takata et al., 2017b). If these approaches can be employed in a human brain organoid culture system, the composition and axis of the brain organoids could become much more similar to that of the actual brain.

Since human brain is an organ that grows, matures, and changes with learning in the duration of the life of a human, it is realistically difficult for brain research to imitate these changes in vitro. Nonetheless, brain organoid studies have gradually started to complete the puzzle of cells present in the brain. Adjusting the proportions and composition of those cells present

\section{REFERENCES}

Alvarez-Buylla, A., and Lim, D. A. (2004). For the long run: maintaining germinal niches in the adult brain. Neuron 41, 683-686. doi: 10.1016/S0896-6273(04)00111-4

Amir, R. E., Van den Veyver, I. B., Wan, M., Tran, C. Q., Francke, U., and Zoghbi, H. Y. (1999). Rett syndrome is caused by mutations in X-linked MECP2, encoding methyl-CpG-binding protein 2. Nat. Genet. 23, 185-188. doi: $10.1038 / 13810$

Azevedo, F. A., Carvalho, L. R., Grinberg, L. T., Farfel, J. M., Ferretti, R. E., Leite, R. E., et al. (2009). Equal numbers of neuronal and nonneuronal cells make the human brain an isometrically scaled-up primate brain. J. Comp. Neurol. 513, 532-541. doi: 10.1002/cne.21974

Bagley, J. A., Reumann, D., Bian, S., and Knoblich, J. A. (2017). Fused dorsalventral cerebral organoids model human cortical interneuron migration. Nat. Methods. 14, 743-751. doi: 10.1038/nmeth.4304 in each region of the brain will be the next hurdle to be overcome. One of the most urgent issues in the research using brain organoids would be to accelerate the formation of neurons, glial and other support cells in order to better mimic the adult brain. A recent study revealed that cerebral organoids correspond to a second-trimester human fetal brain (Kadoshima et al., 2013). Cerebral organoids represented the similar transcriptional patterns of the early-to-mid human fetal brain and epigenomic signatures of the mid-fetal human brain (Luo et al., 2016). To model brain diseases, acquisition of more mature level of brain organoids is required, as many diseases are undetectable at an early age and do not show phenotypes in infancy, adolescence or even in old age. At present, although brain organoids can be cultured for more than 20 months (Sloan et al., 2017), longerterm cultivation is required to achieve the rate of actual human brain maturation. If it was to exceed 1 year in development, such a model system could not be applied in clinical practice. Thus, a technology that can generate mature brain organoids similar to the adult brain structure in short-term rather than longterm cultures is required. Finally, since the brain and nervous system play significant roles in controlling most of the organs in the body, we expect that further studies on their interactions with other organs using an organ-on-a-chip approach will be a future direction of this field, thereby resulting in new insights for fundamental and clinical applications (Wikswo et al., 2013; Zheng et al., 2016; Zhang et al., 2017).

\section{AUTHOR CONTRIBUTIONS}

All authors listed have made a substantial, direct and intellectual contribution to the work, and approved it for publication.

\section{FUNDING}

This study was supported by the Basic Science Research Program through the National Research Foundation of Korea (NRF) funded by the Ministry of Science, ICT and Future Planning of the Republic of Korea (Grant Nos. 2016M3A9B6946835 and 2015R1A5A1009701).
Bain, G., Kitchens, D., Yao, M., Huettner, J. E., and Gottlieb, D. I. (1995). Embryonic stem cells express neuronal properties in vitro. Dev. Biol. 168, 342-357. doi: 10.1006/dbio.1995.1085

Bellail, A. C., Hunter, S. B., Brat, D. J., Tan, C., and Van Meir, E. G. (2004). Microregional extracellular matrix heterogeneity in brain modulates glioma cell invasion. Int. J. Biochem. Cell Biol. 36, 1046-1069. doi: 10.1016/j.biocel.2004.01.013

Bergmann, S., Lawler, S. E., Qu, Y., Fadzen, C. M., Wolfe, J. M., Regan, M. S., et al. (2018). Blood-brain-barrier organoids for investigating the permeability of CNS therapeutics. Nat. Protoc. 13, 2827-2843. doi: 10.1038/s41596-0180066-x

Bershteyn, M., Nowakowski, T. J., Pollen, A. A., Di Lullo, E., Nene, A., Wynshaw-Boris, A., et al. (2017). Human iPSC-derived cerebral organoids model cellular features of lissencephaly and reveal prolonged mitosis of outer radial glia. Cell Stem Cell 20, 435-449.e434. doi: 10.1016/j.stem.2016. 12.007 
Birey, F., Andersen, J., Makinson, C. D., Islam, S., Wei, W., Huber, N., et al. (2017). Assembly of functionally integrated human forebrain spheroids. Nature 545, 54-59. doi: 10.1038/nature22330

Brennand, K. J., Simone, A., Jou, J., Gelboin-Burkhart, C., Tran, N., Sangar, S., et al. (2011). Modelling schizophrenia using human induced pluripotent stem cells. Nature 473, 221-225. doi: 10.1038/nature09915

Carter, R. (2014). The Human Brain Book: An Illustrated Guide to Its Structure, Function, and Disorders. New York, NY: Penguin.

Carvajal-Vergara, X., Sevilla, A., D’Souza, S. L., Ang, Y.-S., Schaniel, C., Lee, D.-F., et al. (2010). Patient-specific induced pluripotent stem-cell-derived models of LEOPARD syndrome. Nature 465, 808-812. doi: 10.1038/nature09005

Cazillis, M., Rasika, S., Mani, S., Gressens, P., and Leliévre, V. (2006). In vitro induction of neural differentiation of embryonic stem (ES) cells closely mimics molecular mechanisms of embryonic brain development. Pediatr. Res. 59, 48-53. doi: 10.1203/01.pdr.0000203566.01600.8c

Chambers, S. M., Fasano, C. A., Papapetrou, E. P., Tomishima, M., Sadelain, M., and Studer, L. (2009). Highly efficient neural conversion of human ES and iPS cells by dual inhibition of SMAD signaling. Nat. Biotechnol. 27, 275-280. doi: $10.1038 /$ nbt.1529

Cho, C.-F., Wolfe, J. M., Fadzen, C. M., Calligaris, D., Hornburg, K., Chiocca, E. A., et al. (2017). Blood-brain-barrier spheroids as an in vitro screening platform for brain-penetrating agents. Nat. Commun. 8:15623. doi: 10.1038/ncomms15623

Choi, H. W., Hong, Y. J., Kim, J. S., Song, H., Cho, S. G., Bae, H., et al. (2017). In vivo differentiation of induced pluripotent stem cells into neural stem cells by chimera formation. PLoS ONE 12:e170735. doi: 10.1371/journal.pone.0170735

Choi, S. H., Kim, Y. H., Hebisch, M., Sliwinski, C., Lee, S., D’Avanzo, C., et al. (2014). A three-dimensional human neural cell culture model of Alzheimer's disease. Nature 515, 274-278. doi: 10.1038/nature13800

Chun, Y. S., Chaudhari, P., and Jang, Y.-Y. (2010). Applications of patientspecific induced pluripotent stem cells; focused on disease modeling, drug screening and therapeutic potentials for liver disease. Int. J. Biol. Sci. 6:796. doi: 10.7150/ijbs.6.796

Conti, L., Pollard, S. M., Gorba, T., Reitano, E., Toselli, M., Biella, G., et al. (2005). Niche-independent symmetrical self-renewal of a mammalian tissue stem cell. PLoS Biol. 3:e283. doi: 10.1371/journal.pbio.0030283

Crain, S. M. (1966). Development of "organotypic" bioelectric activities in central nervous tissues during maturation in culture. Int. Rev. Neurobiol. 9, 1-43.

Crossley, P. H., Martinez, S., and Martin, G. R. (1996). Midbrain development induced by FGF8 in the chick embryo. Nature 380, 66-68. doi: $10.1038 / 380066 a 0$

Cunha, C., Panseri, S., Villa, O., Silva, D., and Gelain, F. (2011). 3D culture of adult mouse neural stem cells within functionalized self-assembling peptide scaffolds. Int. J. Nanomed. 6, 943-955. doi: 10.2147/IJN.S17292

Dang, J., Tiwari, S. K., Lichinchi, G., Qin, Y., Patil, V. S., Eroshkin, A. M., et al. (2016). Zika virus depletes neural progenitors in human cerebral organoids through activation of the innate immune receptor TLR3. Cell Stem Cell 19, 258-265. doi: 10.1016/j.stem.2016.04.014

D'avanzo, C., Aronson, J., Kim, Y. H., Choi, S. H., Tanzi, R. E., and Kim, D. Y. (2015). Alzheimer's in 3D culture: challenges and perspectives. Bioessays 37, 1139-1148. doi: 10.1002/bies.201500063

Davie, C. A. (2008). A review of Parkinson's disease. Br. Med. Bull. 86, 109-127. doi: 10.1093/bmb/ldn013

Dhara, S. K., and Stice, S. L. (2008). Neural differentiation of human embryonic stem cells. J. Cell. Biochem. 105, 633-640. doi: 10.1002/jcb.21891

Dobyns, W. B., Stratton, R. F., Parke, J. T., Greenberg, F., Nussbaum, R. L., and Ledbetter, D. H. (1983). Miller-Dieker syndrome: lissencephaly andmonosomy 17p. J. Pediatr. 102, 552-558. doi: 10.1016/S0022-3476(83) 80183-8

Doi, D., Samata, B., Katsukawa, M., Kikuchi, T., Morizane, A., Ono, Y., et al. (2014). Isolation of human induced pluripotent stem cellderived dopaminergic progenitors by cell sorting for successful transplantation. Stem Cell Rep. 2, 337-350. doi: 10.1016/j.stemcr.2014. 01.013

Dutta, D., and Clevers, H. (2017). Organoid culture systems to study host-pathogen interactions. Curr. Opin. Immunol. 48, 15-22. doi: $10.1016 /$ j.coi.2017.07.012
Eiraku, M., and Sasai, Y. (2012). Mouse embryonic stem cell culture for generation of three-dimensional retinal and cortical tissues. Nat. Protoc. 7, 69-79. doi: 10.1038/nprot.2011.429

Eiraku, M., Takata, N., Ishibashi, H., Kawada, M., Sakakura, E., Okuda, S., et al. (2011). Self-organizing optic-cup morphogenesis in three-dimensional culture. Nature 472, 51-56. doi: 10.1038/nature09941

Eiraku, M., Watanabe, K., Matsuo-Takasaki, M., Kawada, M., Yonemura, S., Matsumura, M., et al. (2008). Self-organized formation of polarized cortical tissues from ESCs and its active manipulation by extrinsic signals. Cell Stem Cell 3, 519-532. doi: 10.1016/j.stem.2008.09.002

Elkabetz, Y., Panagiotakos, G., Al Shamy, G., Socci, N. D., Tabar, V., and Studer, L. (2008). Human ES cell-derived neural rosettes reveal a functionally distinct early neural stem cell stage. Genes Dev. 22, 152-165. doi: 10.1101/gad.1616208

Eugene, E., Cluzeaud, F., Cifuentes-Diaz, C., Fricker, D., Le Duigou, C., Clemenceau, S., et al. (2014). An organotypic brain slice preparation from adult patients with temporal lobe epilepsy. J. Neurosci. Methods 235, 234-244. doi: 10.1016/j.jneumeth.2014.07.009

Farwell, D. G., Shera, K. A., Koop, J. I., Bonnet, G. A., Matthews, C. P., Reuther, G. W., et al. (2000). Genetic and epigenetic changes in human epithelial cells immortalized by telomerase. Am. J. Pathol. 156, 1537-1547. doi: 10.1016/S0002-9440(10)65025-0

Fatehullah, A., Tan, S. H., and Barker, N. (2016). Organoids as an in vitro model of human development and disease. Nat. Cell Biol. 18, 246-254. doi: $10.1038 /$ ncb3312

Franco, S. J., and Müller, U. (2011). Extracellular matrix functions during neuronal migration and lamination in the mammalian central nervous system. Dev. Neurobiol. 71, 889-900. doi: 10.1002/dneu.20946

Gabriel, E., Ramani, A., Karow, U., Gottardo, M., Natarajan, K., Gooi, L. M., et al. (2017). Recent Zika virus isolates induce premature differentiation of neural progenitors in human brain organoids. Cell Stem Cell 20, 397-406.e395. doi: 10.1016/j.stem.2016.12.005

Garavaglia, A., Moiana, A., Camnasio, S., Bolognini, D., Papait, R., Rigamonti, D., et al. (2010). Adaptation of NS cells growth and differentiation to high-throughput screening-compatible plates. BMC Neurosci. 11:7. doi: 10.1186/1471-2202-11-7

Garber, B. B., and Moscona, A. (1972a). Reconstruction of brain tissue from cell suspensions: I. Aggregation patterns of cells dissociated from different regions of the developing brain. Dev. Biol. 27, 217-234. doi: 10.1016/0012-1606(72)90099-1

Garber, B. B., and Moscona, A. (1972b). Reconstruction of brain tissue from cell suspensions: II. Specific enhancement of aggregation of embryonic cerebral cells by supernatant from homologous cell cultures. Dev. Biol. 27, 235-243. doi: 10.1016/0012-1606(72)90100-5

Garcez, P. P., Loiola, E. C., da Costa, R. M., Higa, L. M., Trindade, P., Delvecchio, R., et al. (2016). Zika virus impairs growth in human neurospheres and brain organoids. Science 352, 816-818. doi: 10.1126/science.aaf6116

Glaser, T., Pollard, S. M., Smith, A., and Brüstle, O. (2007). Tripotential differentiation of adherently expandable neural stem (NS) cells. PLOS ONE 2:e298. doi: 10.1371/journal.pone.0000298

Gonzalez, C., Armijo, E., Bravo-Alegria, J., Becerra-Calixto, A., Mays, C. E., and Soto, C. (2018). Modeling amyloid beta and tau pathology in human cerebral organoids. Mol. Psychiatry 23, 2363-2374. doi: 10.1038/s41380-018-0229-8

Gritti, A., Parati, E., Cova, L., Frolichsthal, P., Galli, R., Wanke, E., et al. (1996). Multipotential stem cells from the adult mouse brain proliferate and selfrenew in response to basic fibroblast growth factor. J. Neurosci. 16, 1091-1100. doi: 10.1523/JNEUROSCI.16-03-01091.1996

Hanna, J., Wernig, M., Markoulaki, S., Sun, C.-W., Meissner, A., Cassady, J. P., et al. (2007). Treatment of sickle cell anemia mouse model with iPS cells generated from autologous skin. Science 318, 1920-1923. doi: 10.1126/science.1152092

Hardy, J., and Selkoe, D. J. (2002). The amyloid hypothesis of Alzheimer's disease: progress and problems on the road to therapeutics. Science 297, 353-356. doi: $10.1126 /$ science.1072994

Harrison, R. G., Greenman, M., Mall, F. P., and Jackson, C. (1907). Observations of the living developing nerve fiber. Anat. Rec. 1, 116-128. doi: 10.1002/ar.1090010503

Her, G. J., Wu, H.-C., Chen, M.-H., Chen, M.-Y., Chang, S.-C., and Wang, T.-W. (2013). Control of three-dimensional substrate stiffness to manipulate 
mesenchymal stem cell fate toward neuronal or glial lineages. Acta Biomater. 9, 5170-5180. doi: 10.1016/j.actbio.2012.10.012

Hoadley, L. (1924). The independent differentiation of isolated chick primordia in chorioallantoic grafts: I. The eye, nasal region, otic region, and mesencephalon. Biol. Bull. 46, 281-315. doi: 10.2307/1536697

Hogue, M. J. (1947). Human fetal brain cells in tissue cultures: their identification and motility. J. Exp. Zool. 106, 85-107. doi: 10.1002/jez.1401060104

Hollmann, E. K., Bailey, A. K., Potharazu, A. V., Neely, M. D., Bowman, A. B., and Lippmann, E. S. (2017). Accelerated differentiation of human induced pluripotent stem cells to blood-brain barrier endothelial cells. Fluids Barriers CNS 14:9. doi: 10.1186/s12987-017-0059-0

Hong, Y. J., Kim, J. S., Choi, H. W., Song, H., Park, C., and Do, J. T. (2016). In vivo generation of neural stem cells through teratoma formation. Stem Cells Dev. 25, 1311-1317. doi: 10.1089/scd.2016.0124

Hopkins, A. M., DeSimone, E., Chwalek, K., and Kaplan, D. L. (2015). 3D in vitro modeling of the central nervous system. Prog. Neurobiol. 125, 1-25. doi: 10.1016/j.pneurobio.2014.11.003

Huch, M., Dorrell, C., Boj, S. F., Van Es, J. H., Li, V. S., Van De Wetering, M., et al. (2013). In vitro expansion of single Lgr5+ liver stem cells induced by Wnt-driven regeneration. Nature 494, 247-250. doi: 10.1038/nature11826

Humpel, C. (2015). Organotypic brain slice cultures: a review. Neuroscience 305, 86-98. doi: 10.1016/j.neuroscience.2015.07.086

Iefremova, V., Manikakis, G., Krefft, O., Jabali, A., Weynans, K., Wilkens, R., et al. (2017). An organoid-based model of cortical development identifies non-cellautonomous defects in Wnt signaling contributing to Miller-Dieker syndrome. Cell Rep. 19, 50-59. doi: 10.1016/j.celrep.2017.03.047

Inestrosa, N. C., and Arenas, E. (2010). Emerging roles of Wnts in the adult nervous system. Nat. Rev. Neurosci. 11, 77-86. doi: 10.1038/nrn2755

Ishii, K. (1966). Reconstruction of dissociated chick brain cells in rotationmediated culture. Cytologia 31, 89-98. doi: 10.1508/cytologia.31.89

Itzhaki, I., Maizels, L., Huber, I., Zwi-Dantsis, L., Caspi, O., Winterstern, A., et al. (2011). Modelling the long QT syndrome with induced pluripotent stem cells. Nature 471, 225-229. doi: 10.1038/nature09747

Jeong, G. S., Chang, J. Y., Park, J. S., Lee, S.-A., Park, D., Woo, J., et al. (2015). Networked neural spheroid by neuro-bundle mimicking nervous system created by topology effect. Mol. Brain 8:17. doi: 10.1186/s13041-015-0109-y

Jo, J., Xiao, Y., Sun, A. X., Cukuroglu, E., Tran, H.-D., Göke, J., et al. (2016). Midbrain-like organoids from human pluripotent stem cells contain functional dopaminergic and neuromelanin-producing neurons. Cell Stem Cell 19, 248-257. doi: 10.1016/j.stem.2016.07.005

Kadhim, H. J., Gadisseux, J.-F., and Evrard, P. (1988). Topographical and cytological evolution of the glial phase during prenatal development of the human brain: histochemical and electron microscopic study. J. Neuropathol. Exp. Neurol. 47, 166-188. doi: 10.1097/00005072-198803000-00009

Kadoshima, T., Sakaguchi, H., Nakano, T., Soen, M., Ando, S., Eiraku, M., et al. (2013). Self-organization of axial polarity, inside-out layer pattern, and species-specific progenitor dynamics in human ES cell-derived neocortex. Proc. Natl. Acad. Sci. 110, 20284-20289. doi: 10.1073/pnas.1315 710110

Kanton, S., Boyle, M. J., He, Z., Santel, M., Weigert, A., Sanchís-Calleja, F., et al. (2019). Organoid single-cell genomic atlas uncovers human-specific features of brain development. Nature 574, 418-422. doi: 10.1038/s41586-019-1654-9

Kapur, T. A., and Shoichet, M. S. (2003). Chemically-bound nerve growth factor for neural tissue engineering applications. J. Biomater. Sci. Polym. Ed. 14, 383-394. doi: $10.1163 / 156856203321478883$

Karzbrun, E., Kshirsagar, A., Cohen, S. R., Hanna, J. H., and Reiner, O. (2018). Human brain organoids on a chip reveal the physics of folding. Nat. Phys. 14, 515-522. doi: 10.1038/s41567-018-0046-7

Katt, M. E., Xu, Z. S., Gerecht, S., and Searson, P. C. (2016). Human brain microvascular endothelial cells derived from the BC1 iPS cell line exhibit a blood-brain barrier phenotype. PLOS ONE 11:e0152105. doi: 10.1371/journal.pone.0152105

Kawasaki, H., Mizuseki, K., Nishikawa, S., Kaneko, S., Kuwana, Y., Nakanishi, S., et al. (2000). Induction of midbrain dopaminergic neurons from ES cells by stromal cell-derived inducing activity. Neuron 28, 31-40. doi: 10.1016/s0896-6273(00)00083-0

Kelava, I., and Lancaster, M. A. (2016). Stem cell models of human brain development. Cell Stem Cell 18, 736-748. doi: 10.1016/j.stem.2016.05.022
Kim, H., Park, H. J., Choi, H., Chang, Y., Park, H., Shin, J., et al. (2019). Modeling G2019S-LRRK2 sporadic Parkinson's disease in 3D midbrain organoids. Stem Cell Rep. 12, 518-531. doi: 10.1016/j.stemcr.2019.01.020

Kim, J. S., Hong, Y. J., Choi, H. W., Song, H., Byun, S. J., and Do, J. T. (2017). Generation of in vivo neural stem cells using partially reprogrammed cells defective in in vitro differentiation potential. Oncotarget 8, 16456-16462. doi: 10.18632 /oncotarget.14861

Kostarelos, K., and Novoselov, K. S. (2014). Exploring the interface of graphene and biology. Science 344, 261-263. doi: 10.1126/science.1246736

Kriks, S., Shim, J.-W., Piao, J., Ganat, Y. M., Wakeman, D. R., Xie, Z., et al. (2011). Dopamine neurons derived from human ES cells efficiently engraft in animal models of Parkinson's disease. Nature 480, 547-551. doi: 10.1038/nature10648

Kuwabara, T., Hsieh, J., Muotri, A., Yeo, G., Warashina, M., Lie, D. C., et al. (2009). Wnt-mediated activation of NeuroD1 and retro-elements during adult neurogenesis. Nat. Neurosci. 12, 1097-1105. doi: 10.1038/nn.2360

Lancaster, M. A., and Knoblich, J. A. (2014). Generation of cerebral organoids from human pluripotent stem cells. Nat. Protoc. 9, 2329-2340. doi: $10.1038 /$ nprot.2014.158

Lancaster, M. A., Renner, M., Martin, C.-A., Wenzel, D., Bicknell, L. S., Hurles, M. E., et al. (2013). Cerebral organoids model human brain development and microcephaly. Nature 501, 373-379. doi: 10.1038/nature12517

Lee, H., Shamy, G. A., Elkabetz, Y., Schofield, C. M., Harrsion, N. L., Panagiotakos, G., et al. (2007). Directed differentiation and transplantation of human embryonic stem cell-derived motoneurons. Stem Cells 25, 1931-1939. doi: 10.1634/stemcells.2007-0097

Levenberg, S., Huang, N. F., Lavik, E., Rogers, A. B., Itskovitz-Eldor, J., and Langer, R. (2003). Differentiation of human embryonic stem cells on threedimensional polymer scaffolds. Proc. Natl. Acad. Sci. 100, 12741-12746. doi: 10.1073/pnas. 1735463100

Li, Y., Muffat, J., Omer, A., Bosch, I., Lancaster, M. A., Sur, M., et al. (2017). Induction of expansion and folding in human cerebral organoids. Cell Stem Cell 20, 385-396.e383. doi: 10.1016/j.stem.2016.11.017

Lippmann, E. S., Azarin, S. M., Kay, J. E., Nessler, R. A., Wilson, H. K., Al-Ahmad, A., et al. (2012). Derivation of blood-brain barrier endothelial cells from human pluripotent stem cells. Nat. Biotechnol. 30, 783-791. doi: 10.1038/nbt.2247

Liu, H., Ye, Z., Kim, Y., Sharkis, S., and Jang, Y. Y. (2010). Generation of endodermderived human induced pluripotent stem cells from primary hepatocytes. Hepatology 51, 1810-1819. doi: 10.1002/hep.23626

Luo, C., Lancaster, M. A., Castanon, R., Nery, J. R., Knoblich, J. A., and Ecker, J. R. (2016). Cerebral organoids recapitulate epigenomic signatures of the human fetal brain. Cell Rep. 17, 3369-3384. doi: 10.1016/j.celrep.2016.12.001

Maden, M. (2007). Retinoic acid in the development, regeneration and maintenance of the nervous system. Nat. Rev. Neurosci. 8, 755-765. doi: 10.1038/nrn2212

Madhavan, M., Nevin, Z. S., Shick, H. E., Garrison, E., Clarkson-Paredes, C., Karl, M., et al. (2018). Induction of myelinating oligodendrocytes in human cortical spheroids. Nat. Methods 15, 700-706. doi: 10.1038/s41592-018-0081-4

Malatesta, P., Hartfuss, E., and Gotz, M. (2000). Isolation of radial glial cells by fluorescent-activated cell sorting reveals a neuronal lineage. Development 127, 5253-5263.

Mansour, A. A., Gonçalves, J. T., Bloyd, C. W., Li, H., Fernandes, S., Quang, D., et al. (2018). An in vivo model of functional and vascularized human brain organoids. Nat. Biotechnol. 36, 432-441. doi: 10.1038/nbt.4127

Mariani, J., Simonini, M. V., Palejev, D., Tomasini, L., Coppola, G., Szekely, A. M., et al. (2012). Modeling human cortical development in vitro using induced pluripotent stem cells. Proc. Natl. Acad. Sci. 109, 12770-12775. doi: 10.1073/pnas.1202944109

Marton, R. M., Miura, Y., Sloan, S. A., Li, Q., Revah, O., Levy, R. J., et al. (2019). Differentiation and maturation of oligodendrocytes in human three-dimensional neural cultures. Nat. Neurosci. 22, 484-491. doi: 10.1038/s41593-018-0316-9

Mellios, N., Feldman, D. A., Sheridan, S. D., Ip, J. P., Kwok, S., Amoah, S. K., et al. (2018). MeCP2-regulated miRNAs control early human neurogenesis through differential effects on ERK and AKT signaling. Mol. Psychiatry 23, 1051-1065. doi: $10.1038 / \mathrm{mp} .2017 .86$

Merkle, F. T., Tramontin, A. D., García-Verdugo, J. M., and Alvarez-Buylla, A. (2004). Radial glia give rise to adult neural stem cells in the subventricular zone. Proc. Natl. Acad. Sci. 101, 17528-17532. doi: 10.1073/pnas.0407893101 
Monzel, A. S., Smits, L. M., Hemmer, K., Hachi, S., Moreno, E. L., van Wuellen, T., et al. (2017). Derivation of human midbrain-specific organoids from neuroepithelial stem cells. Stem Cell Rep. 8, 1144-1154. doi: 10.1016/j.stemcr.2017.03.010

Moreno, E. L., Hachi, S., Hemmer, K., Trietsch, S. J., Baumuratov, A. S., Hankemeier, T., et al. (2015). Differentiation of neuroepithelial stem cells into functional dopaminergic neurons in 3D microfluidic cell culture. Lab Chip 15, 2419-2428. doi: 10.1039/C5LC00180C

Moscona, A. (1957). Formation of lentoids by dissociated retinal cells of the chick embryo. Science 125, 598-599. doi: 10.1126/science.125.3248.598

Moscona, A., and Moscona, H. (1952). The dissociation and aggregation of cells from organ rudiments of the early chick embryo. J. Anat. 86(Pt 3), 287-301. doi: 10.1016/0014-4827(52)90077-3

Muguruma, K. (2017). "3D Culture for Self-formation of the cerebellum from human pluripotent stem cells through induction of the isthmic organizer," in Organ Regeneration. Methods in Molecular Biology, Vol. 1597, ed T. Tsuji (New York, NY: Humana Press), 31-41.

Muguruma, K., Nishiyama, A., Kawakami, H., Hashimoto, K., and Sasai, Y. (2015). Self-organization of polarized cerebellar tissue in 3D culture of human pluripotent stem cells. Cell Rep. 10, 537-550. doi: 10.1016/j.celrep.2014.12.051

Mujtaba, T., Piper, D., Kalyani, A., Groves, A., Lucero, M., and Rao, M. (1999). Lineage-restricted neural precursors can be isolated from both the mouse neural tube and cultured ES cells. Dev. Biol. 214, 113-127. doi: 10.1006/dbio.1999.9418

Nakano, T., Ando, S., Takata, N., Kawada, M., Muguruma, K., Sekiguchi, K., et al. (2012). Self-formation of optic cups and storable stratified neural retina from human ESCs. Cell Stem Cell 10, 771-785. doi: 10.1016/j.stem.2012. 05.009

Nestler, E. J., and Hyman, S. E. (2010). Animal models of neuropsychiatric disorders. Nat. Neurosci. 13, 1161-1169. doi: 10.1038/nn.2647

Nicholson, C. (2001). Diffusion and related transport mechanisms in brain tissue. Rep. Prog. Phys. 64, 815-884. doi: 10.1088/0034-4885/64/7/202

Noctor, S. C., Flint, A. C., Weissman, T. A., Dammerman, R. S., and Kriegstein, A. R. (2001). Neurons derived from radial glial cells establish radial units in neocortex. Nature 409, 714-720. doi: 10.1038/35055553

Novak, U., and Kaye, A. H. (2000). Extracellular matrix and the brain: components and function. J. Clin. Neurosci. 7, 280-290. doi: 10.1054/jocn.1999.0212

Nseir, N., Regev, O., Kaully, T., Blumenthal, J., Levenberg, S., and Zussman, E. (2013). Biodegradable scaffold fabricated of electrospun albumin fibers: mechanical and biological characterization. Tissue Eng. C Methods 19, 257-264. doi: 10.1089/ten.tec.2012.0118

Ormel, P. R., Vieira de Sá, R. V., van Bodegraven, E. J., Karst, H., Harschnitz, O., Sneeboer, M. A., et al. (2018). Microglia innately develop within cerebral organoids. Nat. Commun. 9:4167. doi: 10.1038/s41467-018-06684-2

Ozone, C., Suga, H., Eiraku, M., Kadoshima, T., Yonemura, S., Takata, N., et al. (2016). Functional anterior pituitary generated in self-organizing culture of human embryonic stem cells. Nat. Commun. 7:10351. doi: 10.1038/ncomms10351

Park, J. Y., Kim, S. K., Woo, D. H., Lee, E. J., Kim, J. H., and Lee, S. H. (2009). Differentiation of neural progenitor cells in a microfluidic chip-generated cytokine gradient. Stem Cells 27, 2646-2654. doi: 10.1002/stem.202

Park, S. Y., Park, J., Sim, S. H., Sung, M. G., Kim, K. S., Hong, B. H., et al. (2011). Enhanced differentiation of human neural stem cells into neurons on graphene. Adv. Mater. 23, H263-H267. doi: 10.1002/adma.201101503

Paşca, A. M., Sloan, S. A., Clarke, L. E., Tian, Y., Makinson, C. D., Huber, N., et al. (2015). Functional cortical neurons and astrocytes from human pluripotent stem cells in 3D culture. Nat. Methods 12, 671-678. doi: 10.1038/nmeth.3415

Perrier, A. L., Tabar, V., Barberi, T., Rubio, M. E., Bruses, J., Topf, N., et al. (2004). Derivation of midbrain dopamine neurons from human embryonic stem cells. Proc. Natl. Acad. Sci. 101, 12543-12548. doi: 10.1073/pnas.0404700101

Pham, M. T., Pollock, K. M., Rose, M. D., Cary, W. A., Stewart, H. R., Zhou, P., et al. (2018). Generation of human vascularized brain organoids. Neuroreport 29, 588-593. doi: 10.1097/WNR.0000000000001014

Pollard, S. M., Conti, L., Sun, Y., Goffredo, D., and Smith, A. (2006). Adherent neural stem (NS) cells from fetal and adult forebrain. Cereb. Cortex 16, i112i120. doi: $10.1093 /$ cercor/bhj167
Qi, L., Li, N., Huang, R., Song, Q., Wang, L., Zhang, Q., et al. (2013). The effects of topographical patterns and sizes on neural stem cell behavior. PLoS ONE 8:e59022. doi: 10.1371/journal.pone.0059022

Qian, T., Maguire, S. E., Canfield, S. G., Bao, X., Olson, W. R., Shusta, E. V., et al. (2017). Directed differentiation of human pluripotent stem cells to blood-brain barrier endothelial cells. Sci. Adv. 3:e1701679. doi: 10.1126/sciadv. 1701679

Qian, T., Shusta, E. V., and Palecek, S. P. (2019). Methods for Differentiation of Human Pluripotent Stem Cells to Brain Microvascular Endothelial Cells. Google Patents.

Qian, X., Nguyen, H. N., Song, M. M., Hadiono, C., Ogden, S. C., Hammack, C., et al. (2016). Brain-region-specific organoids using mini-bioreactors for modeling ZIKV exposure. Cell 165, 1238-1254. doi: 10.1016/j.cell.2016.04.032

Quadrato, G., Nguyen, T., Macosko, E. Z., Sherwood, J. L., Yang, S. M., Berger, D. R., et al. (2017). Cell diversity and network dynamics in photosensitive human brain organoids. Nature 545, 48-53. doi: 10.1038/nature22047

Radisavljevic, Z., Avraham, H., and Avraham, S. (2000). Vascular endothelial growth factor up-regulates ICAM-1 expression via the phosphatidylinositol $3 \mathrm{OH}$-kinase/AKT/nitric oxide pathway and modulates migration of brain microvascular endothelial cells. J. Biol. Chem. 275, 20770-20774. doi: 10.1074/jbc.M002448200

Radonjić, N. V., Ayoub, A. E., Memi, F., Yu, X., Maroof, A., Jakovcevski, I., et al. (2014). Diversity of cortical interneurons in primates: the role of the dorsal proliferative niche. Cell Rep. 9, 2139-2151. doi: 10.1016/j.celrep.2014.11.026

Raja, W. K., Mungenast, A. E., Lin, Y.-T., Ko, T., Abdurrob, F., Seo, J., et al. (2016). Self-organizing $3 \mathrm{D}$ human neural tissue derived from induced pluripotent stem cells recapitulate Alzheimer's disease phenotypes. PLoS ONE 11:e0161969. doi: 10.1371/journal.pone.0161969

Raya, Á., Rodríguez-Piz,à, I., Guenechea, G., Vassena, R., Navarro, S., Barrero, M. J., et al. (2009). Disease-corrected haematopoietic progenitors from Fanconi anaemia induced pluripotent stem cells. Nature 460, 53-59. doi: $10.1038 /$ nature 08129

Reinbold, R. (1954). Organotypic differentiation of the eye of the chick embryo in vitro. C. R. Seances Soc. Biol. Fil. 148, 1493-1495.

Renner, M., Lancaster, M. A., Bian, S., Choi, H., Ku, T., Peer, A., et al. (2017). Selforganized developmental patterning and differentiation in cerebral organoids. EMBO J. 36, 1316-1329. doi: 10.15252/embj.201694700

Reynolds, B. A., and Weiss, S. (1992). Generation of neurons and astrocytes from isolated cells of the adult mammalian central nervous system. Science 255, 1707-1710. doi: 10.1126/science. 1553558

Ribecco-Lutkiewicz, M., Sodja, C., Haukenfrers, J., Haqqani, A. S., Ly, D., Zachar, P., et al. (2018). A novel human induced pluripotent stem cell blood-brain barrier model: applicability to study antibody-triggered receptor-mediated transcytosis. Sci. Rep. 8:1873. doi: 10.1038/s41598-018-19522-8

Roy, N. S., Cleren, C., Singh, S. K., Yang, L., Beal, M. F., and Goldman, S. A. (2006). Functional engraftment of human ES cell-derived dopaminergic neurons enriched by coculture with telomerase-immortalized midbrain astrocytes. Nat. Med. 12, 1259-1268. doi: 10.1038/nm1495

Ruoslahti, E. (1996). Brain extracellular matrix. Glycobiology 6, 489-492. doi: $10.1093 /$ glycob/6.5.489

Saha, K., and Jaenisch, R. (2009). Technical challenges in using human induced pluripotent stem cells to model disease. Cell Stem Cell 5, 584-595. doi: 10.1016/j.stem.2009.11.009

Sakaguchi, H., Kadoshima, T., Soen, M., Narii, N., Ishida, Y., Ohgushi, M., et al. (2015). Generation of functional hippocampal neurons from self-organizing human embryonic stem cell-derived dorsomedial telencephalic tissue. Nat. Commun. 6:8896. doi: 10.1038/ncomms9896

Sato, T., Vries, R. G., Snippert, H. J., Van De Wetering, M., Barker, N., Stange, D. E., et al. (2009). Single Lgr5 stem cells build crypt-villus structures in vitro without a mesenchymal niche. Nature 459, 262-265. doi: 10.1038/nature07935

Sen, A., Kallos, M. S., and Behie, L. A. (2001). Effects of hydrodynamics on cultures of mammalian neural stem cell aggregates in suspension bioreactors. Ind. Eng. Chem. Res. 40, 5350-5357. doi: 10.1021/ie001107y

Shamir, E. R., and Ewald, A. J. (2014). Three-dimensional organotypic culture: experimental models of mammalian biology and disease. Nat. Rev. Mol. Cell Biol. 15, 647-664. doi: 10.1038/nrm3873 
Shin, W. J., Seo, J. H., Choi, H. W., Hong, Y. J., Lee, W. J., Chae, J. I., et al. (2019). Derivation of primitive neural stem cells from human induced pluripotent stem cells. J. Comp. Neurol. 527, 3023-3033. doi: 10.1002/cne.24727

Shirai, H., Mandai, M., Matsushita, K., Kuwahara, A., Yonemura, S., Nakano, T., et al. (2016). Transplantation of human embryonic stem cell-derived retinal tissue in two primate models of retinal degeneration. Proc. Natl. Acad. Sci. 113, E81-E90. doi: 10.1073/pnas.1512590113

Silva, G. A., Czeisler, C., Niece, K. L., Beniash, E., Harrington, D. A., Kessler, J. A., et al. (2004). Selective differentiation of neural progenitor cells by highepitope density nanofibers. Science 303, 1352-1355. doi: 10.1126/science.10 93783

Sloan, S. A., Darmanis, S., Huber, N., Khan, T. A., Birey, F., Caneda, C., et al. (2017). Human astrocyte maturation captured in 3D cerebral cortical spheroids derived from pluripotent stem cells. Neuron 95, 779-790.e776. doi: 10.1016/j.neuron.2017.07.035

Smith, J. R., Vallier, L., Lupo, G., Alexander, M., Harris, W. A., and Pedersen, R. A. (2008). Inhibition of Activin/Nodal signaling promotes specification of human embryonic stem cells into neuroectoderm. Dev. Biol. 313, 107-117. doi: 10.1016/j.ydbio.2007.10.003

Snow, D. M., and Letourneau, P. C. (1992). Neurite outgrowth on a step gradient of chondroitin sulfate proteoglycan (CS-PG). J. Neurobiol. 23, 322-336. doi: 10.1002/neu.480230311

Stachowiak, E., Benson, C., Narla, S., Dimitri, A., Chuye, L. B., Dhiman, S., et al. (2017). Cerebral organoids reveal early cortical maldevelopment in schizophrenia-computational anatomy and genomics, role of FGFR1. Transl. Psychiatry 7:6. doi: 10.1038/s41398-017-0054-x

Stiles, J., and Jernigan, T. L. (2010). The basics of brain development. Neuropsychol. Rev. 20, 327-348. doi: 10.1007/s11065-010-9148-4

Suga, H., Kadoshima, T., Minaguchi, M., Ohgushi, M., Soen, M., Nakano, T., et al. (2011). Self-formation of functional adenohypophysis in three-dimensional culture. Nature 480, 57-62. doi: 10.1038/nature 10637

Syková, E., and Nicholson, C. (2008). Diffusion in brain extracellular space. Physiol. Rev. 88, 1277-1340. doi: 10.1152/physrev.00027.2007

Takahashi, K., and Yamanaka, S. (2006). Induction of pluripotent stem cells from mouse embryonic and adult fibroblast cultures by defined factors. Cell 126, 663-676. doi: 10.1016/j.cell.2006.07.024

Takata, N., Abbey, D., Fiore, L., Acosta, S., Feng, R., Gil, H. J., et al. (2017a). An eye organoid approach identifies Six3 suppression of R-spondin 2 as a critical step in mouse neuroretina differentiation. Cell Rep. 21, 1534-1549. doi: 10.1016/j.celrep.2017. 10.041

Takata, N., Sakakura, E., Eiraku, M., Kasukawa, T., and Sasai, Y. (2017b). Self-patterning of rostral-caudal neuroectoderm requires dual role of Fgf signaling for localized Wnt antagonism. Nat. Commun. 8:1339. doi: 10.1038/s41467-017-01105-2

Takebe, T., Sekine, K., Enomura, M., Koike, H., Kimura, M., Ogaeri, T., et al. (2013). Vascularized and functional human liver from an iPSC-derived organ bud transplant. Nature 499, 481-484. doi: 10.1038/nature12271

Takebe, T., Zhang, R.-R., Koike, H., Kimura, M., Yoshizawa, E., Enomura, M., et al. (2014). Generation of a vascularized and functional human liver from an iPSC-derived organ bud transplant. Nat. Protoc. 9, 396-409. doi: 10.1038/nprot.2014.020

Tamamaki, N., Nakamura, K., Okamoto, K., and Kaneko, T. (2001). Radial glia is a progenitor of neocortical neurons in the developing cerebral cortex. Neurosci. Res. 41, 51-60. doi: 10.1016/S0168-0102(01)00259-0

Tansley, K. (1933a). Factors affecting the development and regeneration of visual purple in the mammalian retina. Proc. R. Soc. Lond. Ser. B 114, 79-103. doi: 10.1098/rspb.1933.0072

Tansley, K. (1933b). The formation of rosettes in the rat retina. Br. J. Ophthalmol. 17:321. doi: 10.1136/bjo.17.6.321

Temple, S. (1989). Division and differentiation of isolated CNS blast cells in microculture. Nature 340, 471-473. doi: 10.1038/340471a0

Theocharis, A. D., Skandalis, S. S., Gialeli, C., and Karamanos, N. K. (2016). Extracellular matrix structure. Adv. Drug Deliv. Rev. 97, 4-27. doi: 10.1016/j.addr.2015.11.001
Uwamori, H., Higuchi, T., Arai, K., and Sudo, R. (2017). Integration of neurogenesis and angiogenesis models for constructing a neurovascular tissue. Sci. Rep. 7:17349. doi: 10.1038/s41598-017-17411-0

Van der Worp, H. B., Howells, D. W., Sena, E. S., Porritt, M. J., Rewell, S., O'Collins, V., et al. (2010). Can animal models of disease reliably inform human studies? PLoS Med. 7:e1000245. doi: 10.1371/journal.pmed.1000245

Waddington, C. H., and Cohen, A. (1936). Experiments on the development of the head of the chick embryo. J. Exp. Biol. 13, 219-236.

Wagers, A. J., and Weissman, I. L. (2004). Plasticity of adult stem cells. Cell 116, 639-648. doi: 10.1016/S0092-8674(04)00208-9

Watanabe, K., Kamiya, D., Nishiyama, A., Katayama, T., Nozaki, S., Kawasaki, H., et al. (2005). Directed differentiation of telencephalic precursors from embryonic stem cells. Nat. Neurosci. 8, 288-296. doi: 10.1038/nn1402

Welker, W. (1990). "Why does cerebral cortex fissure and fold?" in Cerebral Cortex (Boston, MA: Springer), 3-136.

Wichterle, H., Lieberam, I., Porter, J. A., and Jessell, T. M. (2002). Directed differentiation of embryonic stem cells into motor neurons. Cell 110, 385-397. doi: 10.1016/S0092-8674(02)00835-8

Wikswo, J. P., Curtis, E. L., Eagleton, Z. E., Evans, B. C., Kole, A., Hofmeister, L. H., et al. (2013). Scaling and systems biology for integrating multiple organs-on-a-chip. Lab Chip 13, 3496-3511. doi: 10.1039/c3lc50243k

Xiang, Y., Tanaka, Y., Patterson, B., Kang, Y.-J., Govindaiah, G., Roselaar, N., et al. (2017). Fusion of regionally specified hPSC-derived organoids models human brain development and interneuron migration. Cell Stem Cell 21, 383-398.e387. doi: 10.1016/j.stem.2017.07.007

Yan, Y., Shin, S., Jha, B. S., Liu, Q., Sheng, J., Li, F., et al. (2013). Efficient and rapid derivation of primitive neural stem cells and generation of brain subtype neurons from human pluripotent stem cells. Stem Cells Transl. Med. 2, 862-870. doi: $10.5966 / \mathrm{sctm} .2013-0080$

Yang, J., Cai, J., Zhang, Y., Wang, X., Li, W., Xu, J., et al. (2010). Induced pluripotent stem cells can be used to model the genomic imprinting disorder Prader-Willi syndrome. J. Biol. Chem. 285, 40303-40311. doi: $10.1074 /$ jbc.M110.183392

Yazawa, M., Hsueh, B., Jia, X., Pasca, A. M., Bernstein, J. A., Hallmayer, J., et al. (2011). Using induced pluripotent stem cells to investigate cardiac phenotypes in Timothy syndrome. Nature 471, 230-234. doi: 10.1038/nature09855

Yu, J., Vodyanik, M. A., Smuga-Otto, K., Antosiewicz-Bourget, J., Frane, J. L., Tian, S., et al. (2007). Induced pluripotent stem cell lines derived from human somatic cells. Science 318, 1917-1920. doi: 10.1126/science.1151526

Yui, S., Nakamura, T., Sato, T., Nemoto, Y., Mizutani, T., Zheng, X., et al. (2012). Functional engraftment of colon epithelium expanded in vitro from a single adult Lgr5+ stem cell. Nat. Med. 18, 618-623. doi: 10.1038/nm.2695

Zecevic, N., Chen, Y., and Filipovic, R. (2005). Contributions of cortical subventricular zone to the development of the human cerebral cortex. J. Comp. Neurol. 491, 109-122. doi: 10.1002/cne.20714

Zhang, S.-C., Wernig, M., Duncan, I. D., Brüstle, O., and Thomson, J. A. (2001). In vitro differentiation of transplantable neural precursors from human embryonic stem cells. Nat. Biotechnol. 19:1129. doi: 10.1038/nbt1201-1129

Zhang, Y. S., Aleman, J., Shin, S. R., Kilic, T., Kim, D., Shaegh, S. A. M., et al. (2017). Multisensor-integrated organs-on-chips platform for automated and continual in situ monitoring of organoid behaviors. Proc. Natl. Acad. Sci. 114, E2293-E2302. doi: 10.1073/pnas.1612906114

Zheng, F., Fu, F., Cheng, Y., Wang, C., Zhao, Y., and Gu, Z. (2016). Organon-a-chip systems: microengineering to biomimic living systems. Small 12, 2253-2282. doi: 10.1002/smll.201503208

Conflict of Interest: The authors declare that the research was conducted in the absence of any commercial or financial relationships that could be construed as a potential conflict of interest.

Copyright $\odot 2019$ Hong and Do. This is an open-access article distributed under the terms of the Creative Commons Attribution License (CC BY). The use, distribution or reproduction in other forums is permitted, provided the original author(s) and the copyright owner(s) are credited and that the original publication in this journal is cited, in accordance with accepted academic practice. No use, distribution or reproduction is permitted which does not comply with these terms. 